\title{
ATIVIDADE DE BUPROFEZIN SOBRE A CIGARRINHA VERDE DO FEIJOEIRO, Empoasca kraemeri (Ross \& Moore, 1957) (HEMIPTERA, CICADELLIDAE), EM CONDIÇÕES DE LABORATÓRIO
}

\section{PAULO ROGÉRIO MORENO \\ Engenheiro Agrônomo}

Orientador: Prof. Dr. OCTÁVIO NAKANO

Dissertação apresentada à Escola Superior de Agricultura "Luiz de Queiroz", Universidade de São Paulo, para obtenção do título de Mestre em Ciências, Área de Concentração: Entomologia.

\section{PIRACICABA}

Estado de São Paulo - Brasil

Dezembro - 2000 
Dados Internacionais de Catalogação na Publicação (CIP)

DIVISĀO DE BIBLIOTECA E DOCUMENTAÇÃO - Campus "Luiz de Queiroz"/USP

Moreno, Paulo Rogério
Atividade de buprofezin sobre a cigarrinha verde do feijoeiro, Empoasca kraemeri (Ross \& Moore, 1957) (Hemiptera, Cicadellidae), em condiçōes de laboratório / Paulo Rogério Moreno. - - Piracicaba, 2000.

$68 \mathrm{p}$.

Dissertação (mestrado) - - Escola Superior de Agricultura Luiz de Queiroz, 2000. Bibliografia.

1. Cigarrinha-verde-do-feijāo 2. Controle químico 3. Inseticida 4. Inseto polífago 5. Praga agricola l. Título

CDD 635.652

"Permitida a cópia total ou parcial deste documento, desde que citada a fonte - 0 autor" 


\section{DEDICATÓRIA}

Dedico estes anos de estudo e trabalho a minha familia

Jarbas, Clotildes, Tadeu, Cristina, Leonardo, Rafael, Victor, Érica e Júlia

pelo carinho e amor em todos os meus anos de vida

e ofereço a minha namorada Alexsandra

e meus amigos Rogério, José Carlos e Vivaldo pelo companheirismo

em muitas fases importantes de minha vida. 


\section{AGRADECIMENTOS}

Ao Departamento de Entomologia, Fitopatologia e Zoologia Agrícola da ESALQ/USP pela oportunidade de realizar este curso;

Ao Prof. Dr. Octávio Nakano, pela acolhida como estagiário, orientação durante o mestrado e principalmente pela amizade, confiança e aprendizagem;

Ao CNPq (Conselho Nacional de Desenvolvimento Científico e Tecnológico), pela concessão da bolsa de estudos;

À Hokko do Brasil, nas pessoas dos Srs. Takashi Kavawata e Joil Assis Baldovinotti, pelas idéias e ajuda financeira ao projeto;

Ao Prof. Dr. Celso Omoto, pelas sugestões na dissertação, auxílio durante o curso e pela amizade proporcionada nestes anos de convívio;

Aos Professores do Departamento de Entomologia, Fitopatologia e Zoologia Agrícola da ESALQ/USP pelos ensinos prestados e ajuda no decorrer do curso;

Ao Prof. Dr. Geraldo Papa (FEIS - UNESP) pela correção e sugestões na dissertação;

Ao Prof. Dr. Silvo S. Zocchi do Departamento de Matemática e Estatistica da ESALQ/USP, pelas sugestões e auxílio nas análises estatisticas;

Aos funcionários do Departamento de Entomologia, Fitopatologia e Zoologia Agrícola da ESALQ/USP e em especial ao Téc. Agr. Augusto C. Pinheiro Florin pelo auxilio nos trabalhos;

À pesquisadora Eng. Agr. MSc. Ranyse Barbosa Querino da Silva pela identificação dos insetos;

Enfim, a todas as pessoas que, direta ou indiretamente, contribuiram para o sucesso deste trabalho, o meu sincero agradecimento. 


\section{SUMÁRIO}

Página

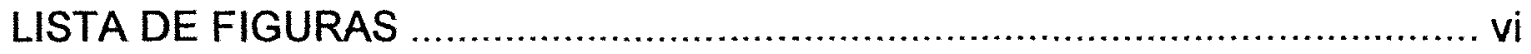

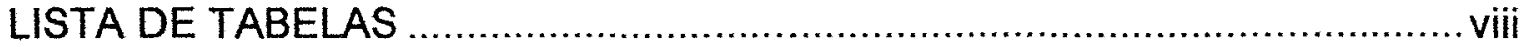

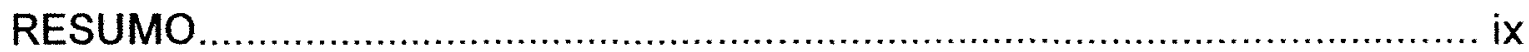

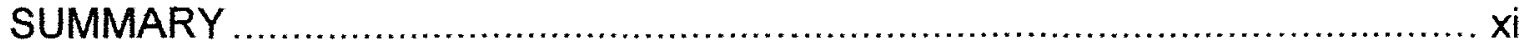

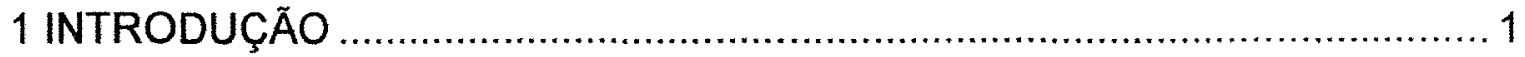

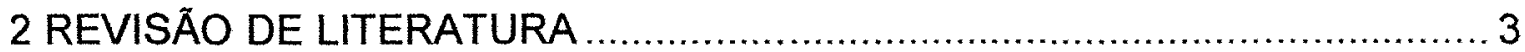

2.1 A cigarrinha verde do feijoeiro - Empoasca kraemeri................................ 5

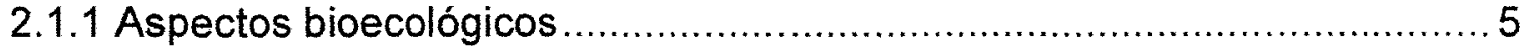

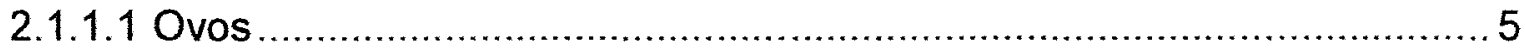

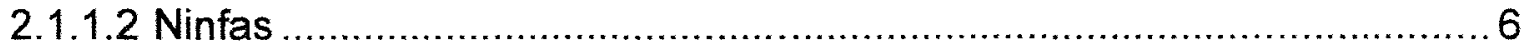

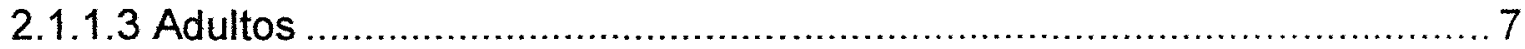

2.1.1.4 Pré-oviposição, oviposição e fecundidade …..................................... 8

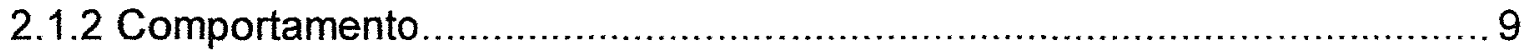

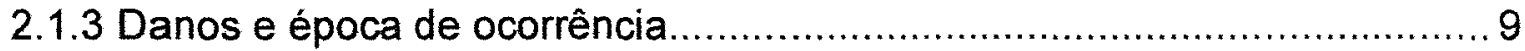

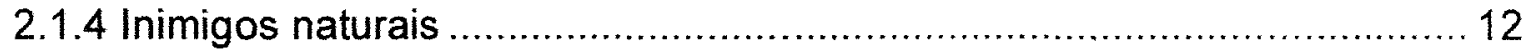

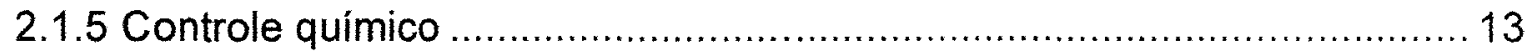

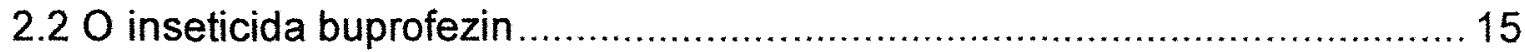

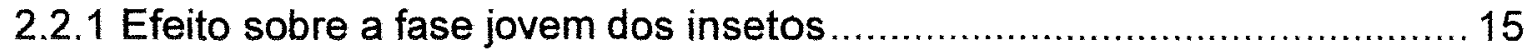

2.2.2 Efeito sobre a fase adulta dos insetos ............................................ 19

2.2.2.1 Importância da prostaglandina no processo de postura ...................... 19

2.2.2.2 Efeito sobre a longevidade e fecundidade ...................................... 21

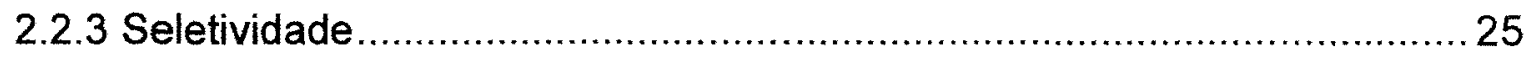

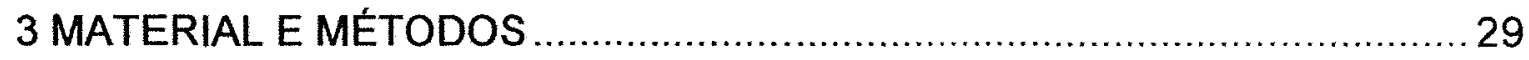

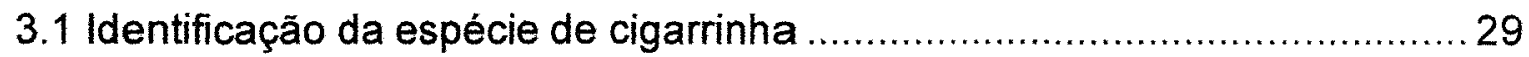

3.2 Criação de Empoasca kraemeri ........................................................... 29

3.3 Efeito de buprofezin sobre ninfas de Empoasca kraemeri em bioensaio de

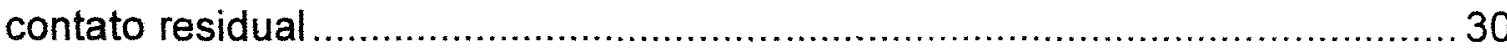


3.4 Efeito de buprofezin sobre adultos de Empoasca kraemeri

3.4.1 Contaminação de casais em diferentes concentrações em bioensaio de contato residual.

3.4.2 Contaminação de machos ou fêmeas em bioensaio de contato residual. 35 4 RESULTADOS E DISCUSSÃO.

4.1 Efeito de buprofezin sobre ninfas de Empoasca kraemeri em bioensaio de contato residual

4.2 Efeito de buprofezin sobre adultos de Empoasca kraemeri

4.2.1 Contaminação de casais em diferentes concentrações em bioensaio de contato residual

4.2.1.1 Efeito sobre a longevidade

4.2.1.2 Efeito sobre a fecundidade.

4.2.2 Contaminação de machos ou fêmeas em bioensaio de contato residual. 47

4.2.2.1 Efeito sobre a longevidade

4.2.2.2 Efeito sobre a fecundidade. 50

5 CONCLUSÕES

REFERÊNCIAS BIBLIOGRÁFICAS 54 APENNDICE 1 


\section{LISTA DE FIGURAS}

Página

1 Placas de petri aberta (A) e fechada (B) utilizadas na condução dos ensaios de mortalidade com ninfas de E. kraemeri, em bioensaio de tratamento com buprofezin através do contato residual

2 Tubos de vidro utilizados para a transferência de adultos de E. kraemeri. 32

3 Planta de feijão em solução nutritiva $(A)$ e pote plástico (B) utilizados na condução de ensaios de contaminação com buprofezin via contato residual com adultos de $E$. kraemeri

4 Mortalidade de ninfas de primeiro instar de E. kraemeri aos 2 dias após o tratamento, em função da exposição em diferentes concentrações de buprofezin, em bioensaio de contato residual

5 Longevidade média em dias para fêmeas, machos e casais adultos de $E$. kraemeri, em função da contaminação em diferentes concentrações de buprofezin, em bioensaio de contato residual

6 Redução na longevidade média para fêmeas e machos adultos de $E$. kraemeri, em função da contaminação em diferentes concentrações de buprofezin, em bioensaio de contato residual

7 Postura e ritmo de postura médios para fêmeas de E. kraemeri, em função da contaminação em diferentes concentrações de buprofezin, em bioensaio de contato residual 
8 Longevidade média em dias para fêmeas, machos e casais adultos de $E$. kraemeri, em função do sexo tratado com buprofezin a 1000 ppm, no bioensaio de contaminação em superfície tratada

9 Redução na longevidade média para fêmeas e machos adultos de $E$. kraemeri, em função do sexo tratado com buprofezin a 1000 ppm, no bioensaio de contaminação em superfície tratada

10 Postura e ritmo de postura médios para fêmeas de E. kraemeri, em função do sexo tratado com buprofezin a 1000 ppm, no bioensaio de contaminação em superfície tratada 


\section{LISTA DE TABELAS}

Página

1 Mortalidade de ninfas de primeiro instar de E. kraemeri aos 2 dias após o tratamento, em função da exposição em diferentes concentrações de buprofezin, em bioensaio de contato residual 38

2 Longevidade média em dias para fêmeas e machos adultos de $E$. kraemeri, em função da exposição em diferentes concentrações de buprofezin, em bioensaio de contato residual

3 Número médio de ovos colocados por parcela (4 casais) e ritmo médio de postura por fêmea de E. kraemeri, em função da exposição em diferentes concentrações de buprofezin, em bioensaio de contato residual

4 Longevidade média em dias para fêmeas e machos adultos de $E$. kraemeri, em função do sexo tratado com buprofezin a 1000 ppm, em bioensaio de contato residual

5 Número médio de ovos colocados por parcela (4 casais) e ritmo médio de postura por fêmea de E. kraemeri, em função do sexo tratado com buprofezin a $1000 \mathrm{ppm}$, em bioensaio de contato residual

6 Dados originais de longevidade de Empoasca kraemeri 67

7 Dados originais de postura e ritmo de postura de Empoasca kraemeri 68 


\title{
ATIVIDADE DE BUPROFEZIN SOBRE A CIGARRINHA VERDE DO FEIJOEIRO, Empoasca kraemeri (Ross \& Moore, 1957) (HEMIPTERA, CICADELLIDAE), EM CONDIÇÕES DE LABORATÓRIO
}

\author{
Autor: PAULO ROGÉRIO MORENO \\ Orientador: Prof. Dr. OCTÁVIO NAKANO
}

\section{RESUMO}

A cigarrinha verde, Empoasca kraemeri, é uma praga muito importante na América Latina e presente com grande freqüência na cultura do feijoeiro comum, Phaseolus vulgaris, sendo necessário recorrer ao controle químico quando a população atinge níveis elevados. Neste trabalho foi estudado o efeito do inseticida buprofezin, um composto inibidor da biossíntese de quitina, sobre a mortalidade de ninfas de primeiro instar desta praga, sob condições de laboratório. Os resultados mostraram que a praga é altamente susceptível ao inseticida, sendo a $\mathrm{CL}_{50}$ estimada de $0,112 \mathrm{ppm}$, com intervalo de confiança $[0,0856 ; 0,1459]$.

Em outro bioensaio, foi estudado o efeito de buprofezin sobre adultos de Empoasca kraemeri. Casais virgens e recém emergidos, foram colocados em contato com plantas de feijão previamente imersas em soluções do inseticida. Foram testadas 3 concentrações: 0,10 e $50 \mathrm{ppm}$. A longevidade média para os insetos no tratamento testemunha foi de 46 e 27 dias, para fêmeas e machos, respectivamente. Para a concentração de $10 \mathrm{ppm}$, a longevidade para fêmeas e machos sofreu redução de 62 e $41 \%$. Resultado semelhante foi observado no tratamento de 50 ppm, com redução na longevidade de 65 e 49\%, para fêmeas 
e machos. Além disto, o resultado mais interessante foi obtido com a avaliação da postura. Foi observada uma média de 102 ovos por fêmea no tratamento testemunha. Para a concentração de 10 e 50 ppm, a média de ovos por fêmea foi de 0,9 e 0,1; respectivamente, ou seja, redução quase que total na postura. Além destes parâmetros, observou-se também o ritmo de postura, pois leva em consideração a longevidade dos indivíduos, encontrando-se os valores de 2,31; 0,09 e 0,01 ovos/fêmea/dia para a testemunha, 10 e 50 ppm de buprofezin, respectivamente.

No último bioensaio, foi investigado o efeito de buprofezin sobre os adultos de Empoasca kraemeri, porém, tratando-se apenas machos ou fêmeas isoladamente com o inseticida em superfície contaminada a $1000 \mathrm{ppm}$ e posteriormente, colocando-os junto a insetos do sexo oposto que não haviam sido contaminados. Foram adotados 3 tratamentos: fêmeas tratadas, machos tratados e testemunha. Foi observado longevidade de 46 e 27 dias para fêmeas e machos no tratamento testemunha. Quando apenas as fêmeas receberam o tratamento inseticida, a longevidade sofreu redução de 24 e $16 \%$, para fêmeas e machos, respectivamente. Entretanto, quando somente os machos foram tratados com buprofezin, foi observada maior redução na longevidade, inclusive nas fêmeas não intoxicadas, ou seja, 41 e 53\% de redução para fêmeas e machos, respectivamente. Notou-se também pequena variação com relação ao total de ovos colocados, porém, o ritmo de postura não apresentou diferenças, sendo de 2,$31 ; 2,56$ e 2,42 ovos/fêmea/dia no tratamento testemunha, fêmeas e macho tratados, respectivamente. A redução na postura foi devido a redução na longevidade das fêmeas, através da contaminação com buprofezin. 


\title{
ACTIVITY OF BUPROFEZIN ON GREEN-LEAFHOPPER, Empoasca kraemeri (Ross \& Moore, 1957) (HEMIPTERA, CICADELLIDAE), UNDER LABORATORY CONDITIONS
}

\author{
Author: PAULO ROGÉRIO MORENO \\ Adviser: Prof. Dr. OCTÁVIO NAKANO
}

\section{SUMMARY}

The green leafhopper, Empoasca kraemeri, is an important pest in Latin America and frequently encountered on drybeans fields, Phaseolus vulgaris. Chemical control is necessary when population reaches the threshold level. First, the effect of buprofezin, a chitin synthesis inhibitor, was evaluated on first instars of this pest, under laboratory conditions. The results showed that the pest is highly susceptible to insecticide, and the estimated $\mathrm{CL}_{50}$ is $0.112 \mathrm{ppm}$, with confidence interval of $[0.0856 ; 0.1459]$. Then, it was investigated the effect of buprofezin against Empoasca kraemeri adults. Virgin pairs of recently emerged adults, were placed in contact with drybeans plants previously treated with buprofezin. It was tested 3 concentrations: 0,10 and $50 \mathrm{ppm}$. The average longevity of insects on untreated plants was 46 and 27 days, to females and males, respectively. At $10 \mathrm{ppm}$, the longevity for females and males showed a decrease of 62 and $41 \%$. Similar results were observed at $50 \mathrm{ppm}$, with longevity decrease of 65 and $49 \%$, to females and males, respectively. Besides, the most interesting results were obtained on fecundity. It was noted an average of 102 eggs per female in the control treatment. For 10 and $50 \mathrm{ppm}$, the average number of eggs per female was 0.9 and 0.01 ; respectively, that is, almost a total egg-laying reduction. Besides these parameters, it was observed that egg laying 
frequency was 2.31 eggs/female/day in the control, 0.09 and 0.01 eggs/female/day, at 10 and $50 \mathrm{ppm}$, respectively.

In the last experiment, it was investigated buprofezin effect against Empoasca kraemeri adults only when female or male was treated with 1,000 ppm of buprofezin and then it was placed in contact with an opposite sex that was not treated with the insecticide. It was observed an average longevity of 46 and 27 days for females and males, respectively in the control treatment. When only female was treated with insecticide, the longevity decreased in 24 and $16 \%$, for females and males, respectively. However, when only males were treated with buprofezin, it was observed higher longevity decrease, even on untreated females with 41 and $53 \%$ of longevity reduction for females and males, respectively. It was observed a small variation on number of eggs, but the egg laying frequency did not show differences among treatments, with values of $2.31,2.56$ and 2.42 eggs/female/day in the control, female- and male-treated, respectively. The egg laying reduction occurred because female showed decrease on longevity caused by buprofezin contamination. 


\section{INTRODUÇÃO}

O feijoeiro comum, Phaseolus vulgaris, apresenta grande importância no panorama agrícola nacional, sendo cultivado tanto por grandes produtores dotados de alta tecnologia, bem como, por pequenos agricultores para o sustento próprio.

Trata-se de um dos produtos mais consumidos pela população brasileira, servindo como fonte alternativa de proteínas, aliado ao seu alto valor energético.

Como em todos os sistemas agrícolas, temos a presença de organismos que prejudicam o desenvolvimento normal da cultura. Dentre estes, destaca-se a cigarrinha verde do feijoeiro, Empoasca kraemeri (Ross \& Moore, 1957), uma praga encontrada em todo o território brasileiro (Vieira, 1983), além de sua presença em outros países da América do Sul e Central (Wilde et al., 1976).

Trata-se de um inseto polífago e bastante agressivo, podendo causar prejuízos consideráveis quando as condições climáticas e o hospedeiro the são favoráveis, visto que, os inimigos naturais associados a praga não são capazes de manter as populações de $E$. kraemeri abaixo do nivel de dano econômico. Nestas condições, tornam-se necessárias as intervenções por parte dos agricultores, que acabam recorrendo ao controle químico, utilizando na maior parte das vezes, inseticidas organofosforados que apresentam bom efeito sobre a praga. Entretanto, estes produtos são na maioria dos casos, bastante tóxicos ao homem, sendo os principais responsáveis por intoxicações no campo. Além disto, a presença constante da praga em nossas culturas e o repetitivo uso de 
compostos deste grupo químico, podem levar à seleção de indivíduos resistentes e conseqüentes problemas no controle desta praga.

Torna-se necessário ensaios visando a utilização de novos compostos, com características mais desejáveis como: sítio de ação diferenciado, baixa toxicidade ao homem, seletividade aos inimigos naturais, não agressividade ao meio ambiente, além de alta eficiência no controle da praga. Como possivel alternativa, pode-se citar o inseticida de nome técnico buprofezin, cujo nome comercial em registro no Brasil é Applaud $250^{\circledR}$. Trata-se de um composto inibidor da biossíntese de quitina, portanto, pertencente ao grupo dos reguladores de crescimento dos insetos, com eficiência comprovada sobre representantes da Ordem Hemiptera, entre eles: cigarrinhas, moscas-brancas e cochonilhas (Shibuya, 1984).

O buprofezin interfere na polimerização de $\mathrm{N}$-acetil-D-glucosamino durante formação de UDP-N-acetil-D-glucosamino, ou seja, a quitina. Desta forma, os insetos chegam a morte no momento de realizarem a ecdise, pois 0 exoesqueleto formado não apresenta a rigidez necessária para suportar o processo de muda (Uchida et al., 1985). Além deste modo de ação direto sobre as formas jovens dos insetos, já está comprovado que a contaminação de formas adultas de algumas espécies, leva a redução na postura e eclosão de ninfas, bem como baixa sobrevivência dos descendentes em situações em que os parentais foram tratados com buprofezin (Uchida et al., 1987). Além disto, pode-se destacar outras características deste produto como: baixa toxicidade para mamíferos, visto que a $\mathrm{DL}_{50}$ aguda oral para ratos é de $2198 \mathrm{mg} / \mathrm{kg}$, alta especificidade no controle de pragas e alta seletividade aos inimigos naturais.

Surgiu então, a possibilidade em se utilizar este composto sobre Empoasca kraemeri, com o objetivo de verificar a ação letal sobre ninfas, bem como o efeito sobre adultos, levando-se em consideração a longevidade e fecundidade sobre esta fase da praga.

${ }^{\circledR}$ Marca Registrada da Hokko do Brasil Indústria Química e Agropecuária Ltda. 


\section{REVISÃO DE LITERATURA}

Duas espécies de feijão são muito cultivadas no Brasil: Phaseolus vulgaris, o feijão comum e Vigna unguiculata, vulgarmente conhecido como feijão de corda, feijão macassar, caupi, entre outros (Vieira, 1983).

Segundo dados da CONAB (2000) estima-se que a área plantada em todo o Brasil na safra $99 / 00$ com o feijão comum foi de 4.393 .400 ha, área esta, $4 \%$ inferior à plantada na safra passada. A produção estimada para a safra $99 / 00$ é de 3.076 .900 toneladas de grãos, equivalente a um aumento de $7,2 \%$ em relação a safra 98/99. Nota-se que o rendimento médio vem aumentando a cada safra, pois em $98 / 99$ foi de $627 \mathrm{~kg} / \mathrm{ha}$ e na safra 99/00 estima-se um rendimento médio de $700 \mathrm{~kg} / \mathrm{ha}$. Segundo dados do IBGE (1998), o maior rendimento na safra $97 / 98$ foi obtido no Distrito Federal (1879 kg/ha) e o menor foi observado no Estado do Piauí, com apenas $94 \mathrm{~kg} / \mathrm{ha}$.

Considerando-se a área colhida, tem-se em ordem decrescente os cinco primeiros Estados produtores do Brasil que são: Paraná, Bahia, Minas Gerais, Ceará e Santa Catarina. Em termos de produção, os maiores Estados brasileiros são: Paraná, Minas Gerais, São Paulo, Bahia e Goiás, também em ordem decrescente (IBGE, 1998).

Os grãos do feijoeiro comum constitui-se num alimento básico e na fonte de proteína mais acessível ao povo brasileiro e de grande parte da América Latina. Além de apresentar alto conteúdo energético, seu teor de proteínas varia de 15 a $33 \%$, sendo que a maioria dos cultivares nacionais apresentam composição aproximada de 20 a $25 \%$ deste composto (Fancelli, 1990). 
Dentre as espécies de Phaseolus vulgaris, temos uma acentuada variação de hábitos de crescimento, formas de sementes, cores de tegumento $e$ textura de vagens, devido a intensa pressão de seleção e a expansão de cultivo a distintas faixas de temperatura ocorridas na América Central e do Sul, desde a sua domesticação (Fancelli, 1990).

Todas as linhagens de feijoeiro podem ser atacadas durante o ciclo pela espécie Empoasca kraemeri (Ross \& Moore, 1957), comumente conhecida por cigarrinha verde do feijoeiro. Na língua inglesa esta espécie é chamada vulgarmente de "green leafhopper" e como "lorito verde" na língua espanhola.

Esta praga é considerada por alguns autores como uma das mais importantes para a cultura no Brasil (Ramalho, 1978; Moraes et al., 1980; Vieira, 1983). Outros preferem caracterizá-la como a mais importante na América Central e do Sul (Wilde et al., 1976) e para alguns pesquisadores, este pequeno inseto é considerado como o mais importante no mundo para a cultura do feijão (Vieira, 1983). Trata-se de um inseto polífago, podendo atacar além do feijoeiro comum, outras culturas como amendoim, caupi (Gallo et al., 1988), soja (Vieira, 1983), algodão, batata, cevada, milho, alfafa, fumo e pelo menos outras 80 espécies de plantas não cultivadas (Ospina, 1980).

De acordo com Gallo et al. (1988) a cigarrinha verde do feijoeiro ocupa a seguinte posição taxonômica:

- Classe: Insecta

- Ordem: Hemiptera

- Subordem: Homoptera

- Divisão: Auchenorrhyncha

- Superfamília: Cicadelloidea

- Família: Cicadellidae

- Subfamilia: Typhlocibinae

- Gênero: Empoasca

- Espécie: Empoasca kraemeri 


\subsection{A cigarrinha verde do feijoeiro - Empoasca kraemeri}

\subsubsection{Aspectos bioecológicos}

\subsubsection{Ovos}

Segundo Segnini \& Montagne (1986a), os ovos de Empoasca kraemeri são colocados no interior do tecido da planta, ficando protegidos contra os fatores ambientais adversos. Avaliando-se os ovos nas folhas, notou-se que todos estavam na face inferior do limbo e mais de $90 \%$ na união das nervuras com a lâmina foliar.

Para Wilde et al. (1976) as cigarrinhas evitam tecidos fisiologicamente jovens ou muito velhos, preferindo folhas em estágio médio de desenvolvimento. Estas observações concordam com os resultados obtidos por Ramalho \& Ramos (1979), que fizeram a coleta de plantas de feijão com 35 dias após a semeadura no campo, fazendo a contagem dos ovos no laboratório. Estes autores constataram que as cigarrinhas preferem colocar os ovos nas folhas cotiledonares e $1^{a}$ a $3^{a}$ trifoliadas. Nestes casos, $40,1 \%$ dos ovos foram encontrados na nervura secundária, $39,9 \%$ na nervura terciária, $10,9 \%$ no pecíolo e ráquis, $3,8 \%$ na nervura principal, $3,5 \%$ no pulvino e $1,8 \%$ no mesófilo foliar. Em relação ao caule, o terço mediano foi o que recebeu o maior número de posturas.

De acordo com Wilde et al. (1976), $82 \%$ dos ovos foram colocados no pecíolos do cultivar de feijão comum, o Brasil 3624.

Os ovos apresentam-se alargados e ligeiramente curvos, com comprimento médio de $0,79 \pm 0,09 \mathrm{~mm}$ (Segnini \& Montagne, 1986a) a 0,95 $\mathrm{mm}$ e largura de $0,15 \mathrm{~mm}$ (Wilde et al., 1976).

Para Segnini \& Montagne (1986a) o período médio de incubação a $25 \pm$ $1^{\circ} \mathrm{C}$ foi de $6,94 \pm 0,9$ dias, com intervalo de 6,5 a 11,5 dias, sendo que, $95 \%$ das 
eclosões ocorreram entre 6,5 e 8,0 dias. Para Leite Filho \& Ramalho (1979), o período de incubação dos ovos encontrado foi de $6,97 \pm 0,38$ dias, a $27 \pm 1^{\circ} \mathrm{C}$.

Os primeiros ovos começaram a aparecer em condições de campo na terceira semana após a semeadura do feijoeiro comum (Segnini \& Montagne, 1986b).

Os ovos somente podem ser observados recorrendo-se a técnicas de clareamento do tecido foliar (Ospina, 1980). Para isto, as folhas devem ser colocadas por 3 minutos em solução fervente de lactofenol, cuja composição é: uma parte cada de ácido láctico $85 \%$, fenol e água destilada e duas partes de glicerina. Este procedimento leva ao clareamento das nervuras e a coagulação das proteínas dos ovos, revelando o contorno destes (Carlson \& Hibbs, 1962).

\subsubsection{Ninfas}

As ninfas apresentam a forma do corpo parecido com o adulto, porém são menores, verde claras e não apresentam asas (Ospina, 1980). São reconhecidas facilmente pois locomovem-se lateralmente (Gallo et al., 1988) e se não perturbadas, preferem ficar paradas nos ângulos formados pela união das nervuras (Segnini \& Montagne, 1986a). Além destes autores, Wilde et al. (1976) constataram a presença de 5 instares ninfais. O período médio de desenvolvimento nesta fase foi de $8,45 \pm 0,58$ dias $\left(25 \pm 1^{\circ} \mathrm{C}\right.$ ) (Segnini \& Montagne, 1986a) e de 9,5 \pm 1,5 para Wilde et al. (1976). Para estes autores não ocorreram diferenças no período de desenvolvimento ninfal entre machos e fêmeas. Segundo Pedrosa (1977), o período médio de desenvolvimento ninfal foi um pouco mais longo, ou seja, 13,9 dias em condições de laboratório à temperatura ambiente.

Os estágios ninfais podem ser diferenciados pela cobertura oferecida pelas pequenas asas sobre o $1^{\circ}, 2^{a}$ e $4^{\circ}$ segmento abdominal, para os $3^{2}$, $4^{\circ}$ e $5^{\circ}$ estágios ninfais, respectivamente (Wilde et al., 1976). 
Nos estudos realizados por Leite Filho \& Ramalho (1979), 12\% das ninfas de Empoasca kraemeri criadas em feijoeiro comum e em feijão de corda, apresentaram até 6 instares, quando mantidas em condições de laboratório a $27 \pm 1^{\circ} \mathrm{C}$. Estes autores encontraram um período médio do estágio ninfal de $8,43 \pm 1,0$ dias, quando criadas em plantas de feijão comum.

Pizzamiglio (1979) obteve ninfas de até sétimo instar, porém, em um percentual muito baixo, ou seja, 3,77\% e grande parte dos insetos $(30,2 \%)$ alcançaram o sexto instar, quando criados em pecíolos de feijoeiro comum e mantidos em condições de laboratório a $28 \pm 1^{\circ} \mathrm{C}$. Apesar da ocorrência de um maior número de instares, o período médio de desenvolvimento na fase ninfal foi de 8,97 dias nesta mesma temperatura.

As primeiras ninfas começaram a aparecer em condições de campo entre a terceira e quarta semana após a semeadura do feijoeiro comum (Segnini \& Montagne, 1986b).

\subsubsection{Adultos}

Segundo Vieira (1983) e Gallo et al. (1988) os adultos são verdes e têm aproximadamente $3 \mathrm{~mm}$ de comprimento. Segnini \& Montagne (1986a) constataram longevidade média de $42,40 \pm 26,72$ dias $\left(25 \pm 1^{\circ} \mathrm{C}\right)$, não havendo diferenças entre os sexos. Para Wilde et al. (1976) a longevidade média de fêmeas foi de 64,8 dias, com intervalo de 14 a 80 dias. Os machos viveram em média 58,2 dias, com um mínimo de 13 e máximo de 86 dias a $20 \pm 2^{\circ} \mathrm{C}$. Para Leite Filho \& Ramalho (1979), a longevidade para fêmeas e machos foi de $36,76 \pm 24,86$ e $39,14 \pm 25,37$ dias, respectivamente.

As fêmeas são ligeiramente mais largas que os machos, entretanto, a diferenciação entre sexos é conseguida pela observação do ovipositor nas fêmeas (Ospina, 1980 e Wilde et al., 1976). 
Em estudos de dinâmica populacional conduzidos por Segnini \& Montagne (1986b), concluiu-se que os adultos de cigarrinha verde começaram a chegar na cultura na primeira semana após a semeadura. Desde este período até 8 semanas, as taxas de entrada e saída de adultos não apresentaram diferenças significativas. Entretanto, a partir da $9^{a}$ semana notou-se maior saída do que entrada de insetos na cultura, principalmente de fêmeas.

É interessante ressaltar que $o$ aumento na taxa de saída dos insetos foi observado mesmo com a cultura apresentando bom estado fisiológico para a permanência da praga (Segnini \& Montagne, 1986d).

A colonização pelos adultos começou pelas bordaduras e atingiu os maiores níveis também nesta porção, sendo que o centro da cultura sempre apresentou a menor população da praga (Segnini \& Montagne (1986c).

Para Wilde et al. (1976), Pedrosa (1977), Leite Filho \& Ramalho (1979), Pizzamiglio (1979) e Segnini \& Montagne (1986a), a proporção sexual encontrada em condições de laboratório foi de $1: 1$.

Em condições de campo Segnini \& Montagne (1986b) notaram que a proporção de fêmeas é maior que a de machos no início da infestação. A medida que a população se estabelece, a proporção torna-se praticamente $1: 1$ e os machos passam a prevalecer no final do ciclo da cultura. Talvez isto seja explicado pela maior quantidade de fêmeas que deixam a cultura nesta fase para colonizar novas plantações (Segnini \& Montagne, 1986d).

\subsubsection{Pré-oviposição, oviposição e fecundidade}

Segundo Leite Filho \& Ramalho (1979), o período de pré-oviposição foi de $3,19 \pm 0,67$ dias quando as cigarrinhas foram mantidas a $27 \pm 1^{\circ} \mathrm{C}$. Tal resultado concorda com o anteriormente obtido por Pedrosa (1977) que encontrou um período médio de pré-oviposição de 3,55 dias, com intervalo de 1 a 7 dias. 
O número médio de ovos encontrado por fêmea foi de $123 \pm 93,81$ (Leite Filho \& Ramalho, 1979). Para estes autores o período de oviposição variou de 4 a 76 dias, sendo que os maiores índices foram constatados entre 5 e 34 dias. Para Wilde et al. (1976) o número médio de ovos colocados por fêmea durante a vida foi de 107,2 com variação de 13 a 168 ovos.

Heyer et al. (1991) notaram que fêmeas de Empoasca kraemeri, mantidas em laboratório a $25-26^{\circ} \mathrm{C}$ por várias gerações, colocaram em média 142 ovos. Entretanto, quando foi feita a coleta dos insetos no campo, os quais foram mantidos no laboratório por pouco tempo e avaliada a postura, notou-se que cada fêmea colocou em média somente 88 ovos.

\subsubsection{Comportamento}

Os estágios de ninfa e adulto apresentam geotropismo negativo e fototropismo positivo (Wilde et al., 1976).

Para Bortoli et al. (1986), a cigarrinha verde ataca preferencialmente os terços médio e superior das plantas, sendo portanto, estes os melhores lugares para se fazer a amostragem desta praga no feijoeiro comum. Entretanto, no trabalho conduzido por Heyer \& Dammer (1996) em Cuba, foi observado que até os 33 dias da emergência das plantas de feijoeiro comum, as folhas do terço inferior eram as mais colonizadas por ninfas e adultos de Empoasca kraemeri e após este período, os indivíduos concentraram-se no terço mediano das plantas.

\subsubsection{Danos e época de ocorrência}

Os danos provocados pela cigarrinha verde ao feijoeiro são de ordem física, como consequêencia da penetração do estilete no floema da planta, ocasionando a desorganização e granulação das células e obstrução dos vasos condutores de seiva (Ospina, 1980). Além disto, ocorre também a injeção de 
substâncias toxicogênicas durante a alimentação (Pereira et al., 1993 e Moraes et al., 1980). Segundo estes autores, altas infestações da praga levam ao enfezamento das plantas, que passam a mostrar as bordas dos folíolos viradas para baixo. Em casos mais severos, ocorre o amarelecimento das margens dos folíolos e posterior secamento destas estruturas (Caetano et al., 1987), chegando também a causar redução no porte das plantas (Pizzamiglio, 1979).

Segundo Ramalho (1978), as infestações de cigarrinha verde em $P$. vulgaris cultivar IPA-7419, causaram prejuízos mais acentuados em plantas com 16 a 36 dias de idade. Para Pedrosa (1977), que utilizou o cultivar Rosinha, o período crítico ao ataque compreendeu desde a formação das primeiras folhas trifoliares até a fase de florescimento, para os chamados feijão das águas e da seca.

De uma forma geral, os prejuízos são mais acentuados para o chamado feijão da seca e quando a infestação encontra-se elevada desde o início de desenvolvimento da cultura até o florescimento; também porque nesta época, o número de hospedeiros da praga torna-se reduzido, fazendo com que grande parte dos insetos migrem para o feijoeiro (Bortoli et al., 1986).

Segundo Magalhães et al. (1988), estudando a flutuação populacional da praga no Estado de Goiás durante três anos consecutivos, notou-se que a maior incidência de ninfas e adultos desta praga ocorreram no período de florescimento do feijoeiro. Segnini \& Montagne (1986b), também concluíram que o maior nível populacional foi encontrado durante a época de florescimento e no feijão das secas, quando comparado ao feijão das águas. Tal fato concorda com o obtido por Pereira (1987) que também observou que os maiores índices populacionais da praga ocorreram na época do florescimento, entretanto, com maior intensidade no cultivo do feijão das águas.

Para Segnini \& Montagne (1986b), as chuvas prejudicaram a população de cigarrinha verde devido ao aumento na umidade relativa e favorecimento de fungos entomopatogênicos, provavelmente do gênero Conidiobulus. 
Segundo Oliveira et al. (1981), as maiores infestações de ninfas de cigarrinha verde, tanto em feijoeiro comum como em feijão caupi, ocorreram na época das chuvas, que corresponde ao inverno do nordeste brasileiro, onde foi conduzido o trabalho.

Considerando-se o feijão de corda, foi constatado que o não controle da cigarrinha verde durante todo o ciclo da cultura, levou a redução no rendimento em $60 \%$, quando comparado ao tratamento em que a praga foi controlada quimicamente desde os 8 até 76 dias da emergência (Moraes et al., 1980). Tal fato deveu-se basicamente à drástica redução no número de vagens obtidas no tratamento testemunha. Concluiu-se também que, o início da fase crítica de ataque desta praga deu-se a partir dos 16 dias após a emergência da cultura, não sendo possível estabelecer qual o limite crítico máximo de ataque da praga neste trabalho.

Segundo Mendez et al. (1984), a fase crítica de ataque da cigarrinha verde sobre dois cultivares de feijoeiro comum (Cv. Dial Calima e EMP81), compreendeu de 14 até 28 dias após a semeadura, coincidindo com a fase vegetativa e pouco antes da fase de florescimento, que iniciou aos 28 dias após a semeadura para os cultivares estudados.

Oliveira et al. (1995) demonstraram que o cultivo consorciado de feijão caupi e milho, em diferentes proporções, desde 25 até $75 \%$ de milho, reduziram o número de ninfas de cigarrinhas verdes sobre o caupi, quando comparado ao sistema de monocultivo.

Em trabalho de campo conduzido por Heyer et al. (1989) em Cuba, chegou-se a conclusão de que o controle de Empoasca kraemeri deve ser iniciado assim que as ninfas da primeira geração atingirem nível populacional de 15 a 20/100 trifólios. 


\subsubsection{Inimigos naturais}

Em condições de campo é comum a ocorrência de parasitóides de ovos de Empoasca kraemeri, como por exemplo Anagrus spp. (Hymenoptera, Mymaridae), porém, não são capazes de manter a população da praga abaixo do nível de dano econômico (Ospina, 1980). Segundo Segnini \& Montagne (1986a), além deste parasitóide, podemos encontrar também algumas espécies do gênero Gonatocerus (Hymenoptera, Mymaridae), parasitando ovos de cigarrinha verde. Estes organismos também foram constatados no trabalho de Wilde et al. (1976). Neste caso, $71 \%$ dos ovos provenientes de plantas coletadas no campo continham estes parasitóides.

Pizzamiglio (1979) notou a ocorrência de microhimenópteros parasitas de ovos identificando-os como Anagrus flaveolus (Whaterhouse, 1913) (Hymenoptera, Mymaridae) e Aphelinoidea plutella (Girlt., 1912) (Hymenoptera, Trichogrammatidae). Segundo o autor, estes microhimenópteros preferem parasitar ovos depositados no caule e pecíolo, visto que, foram encontrados $51 \%$ dos ovos parasitados nestas estruturas pelas duas espécies. Já nas folhas, o parasitismo total foi de apenas $0,94 \%$.

O sistema de plantio também influencia o parasitismo de ovos por Anagrus spp.. Tal fato foi comprovado por González \& Cave (1997), pois notaram que no feijão conduzido no sistema de plantio direto, o parasitismo encontrado foi de $35,4 \%$ ao passo que, no plantio convencional o parasitismo foi de apenas $18,5 \%$. Notou-se também que, quanto maior o número de ovos de Empoasca kraemeri, maior a porcentagem de parasitismo por Anagrus spp., o que coincide com a época de florescimento do feijoeiro comum na maior parte das vezes. Concluiu-se também que, a chuva interfere negativamente na eficiência do parasitóide contribuindo com a mortalidade e dificultando a busca pelos ovos do hospedeiro. 
Meyerdirk \& Moratorio (1987), estudando a flutuação populacional da espécie Anagrus girauti (Hymenoptera: Mymaridae), verificaram picos máximos de parasitismo sobre ovos de Empoasca solana, E. abruptor e Circulifer tenellus (Himenoptera: Cicadellidae) em beterraba açucareira de 70,5; 96,2 e 83,5\% em 1983, 84 e 85 , respectivamente, sem distinção para as espécies hospedeiras.

Com relação aos fungos, uma espécie com grande patogenicidade sobre Empoasca kraemeri é sem dúvida, Zoophtora radicans. Entretanto, notamos grandes diferenças no comportamento de diferentes isolados desta espécie sobre ninfas da praga (Leite et al.,1996). No trabalho desenvolvido por estes autores, constatou-se que o isolado mais patogênico foi o ARS-1590, coletado no Estado de Goiás sobre Empoasca sp.. Este isolado apresentou $\mathrm{CL}_{50}$ de 0,67 conídios $/ \mathrm{mm}^{2}$ e CL9o de 8,52 conídios $/ \mathrm{mm}^{2}$.

\subsubsection{Controle químico}

Em ensaio visando o controle da cigarrinha verde com a aplicação de inseticidas granulados no sulco de plantio, Bortoli \& Giacomini (1981), observaram que a melhor eficácia, bem como o maior incremento na produção quando comparado ao tratamento testemunha, foi obtido com a aplicação de aldicarbe na dose de $4,0 \mathrm{~kg}$ i.a./ha. Turati et al. (1982), nesta mesma modalidade de aplicação, observaram que o melhor tratamento para o controle da cigarrinha verde foi o mesmo produto aldicarbe, entretanto, em doses menores, ou seja, 1,$0 ; 1,5$ e $2,0 \mathrm{~kg}$ i.a./ha. Estes tratamentos mostraram eficiência entre 80 e $87 \%$ sobre a praga em questão e incremento na produção de 54,$5 ; 97,7$ e $88,2 \%$, respectivamente, em relação ao tratamento testemunha. Estes dados conferem em parte com o obtido por Vivarelli et al. (1985), pois observaram também que aldicarbe $(1,0 \mathrm{~kg}$ i.a./ha no sulco de plantio) e tiodicarbe $(1,5 \mathrm{~kg}$ i.a. $/ 100 \mathrm{~kg}$ de sementes) mostraram eficiência de $80 \%$ sobre a praga até 28 dias da semeadura. Em outro trabalho com inseticidas granulados aplicados na ocasião do plantio, concluiu-se que os inseticidas 
aldicarbe $(0,60 \mathrm{~kg}$ i.a./ha), dissulfoton $(3,0 \mathrm{~kg}$ i.a./ha), forato $(0,50 \mathrm{~kg}$ i.a./ha) e carbofuran (1,0 kg i.a./ha), mostraram grande incremento na produção do feijão macassar em local com grande incidência da cigarrinha verde, quando comparados ao tratamento testemunha (Costa et al., 1986).

Segundo Caetano et al. (1987), realizando experimento visando somente o efeito de choque dos inseticidas sobre a cigarrinha verde, concluíram que os tratamentos: fenpropatrin ( $90 \mathrm{~g}$ i.a./ha), metamidofós (150 g i.a./ha), ciflutrin (10 $\mathrm{g}$ i.a./ha), acefato (125 g i.a./ha) e monocrotofós (200 g i.a./ha) mostraram eficiência próximo a $100 \%$ aos 3 dias após a aplicação.

Para Lacerda et al. (1988), foram necessárias três aplicações dos produtos monocrotofós e dimetoato, ambos na formulação $40 \% \mathrm{CE}$, nas dosagens de 20 e $66 \mathrm{~g}$ i.a./100 litros de calda, respectivamente, para manter a população de cigarrinha verde abaixo do nivel de controle (8 ninfas/100 folíolos), durante o período crítico de ataque desta praga, ou seja, dos 22 aos 64 dias após a germinação. Para esta mesma condição, foram necessárias duas aplicações do produto metamidofós $60 \%$ CE a $160 \mathrm{~g}$ i.a./100 litros.

Pereira et al. (1993), em seu trabalho visando o controle químico de $E$. kraemeri em feijão caupi, demonstraram que os melhores resultados foram obtidos com os produtos monocrotofós ( $200 \mathrm{~g}$ i.a./ha) na formulação suspensão concentrada e cipermetrina ( $7,5 \mathrm{~g}$ i.a./ha) na formulação eletrodinâmica. Estes tratamentos mostraram alta eficiência no controle de ninfas da praga até os 14 dias da aplicação.

Em trabalho de campo visando o controle da cigarrinha verde em feijoeiro comum, Mayrink et al. (1994) observaram que os seguintes tratamentos químicos (g i.a./ha): esfenvalerato (7,5 e 10,0), fenitrotion (500 e 750) e fenpropatrin (90 e 120), com apenas uma pulverização, mostraram eficiência de controle sobre ninfas da praga entre 89 e $96 \%$, aos 10 dias após o tratamento. 


\subsection{0 inseticida buprofezin}

O inseticida de nome técnico buprofezin (2-tert-butilimino-3-isopropil-5fenil-3,4,5,6-tetrahidro-2H-1,3,5-tiadiazin-4-one) foi descoberto e desenvolvido pela Nihon Nohyaku Co., Ltd., Tokyo, Japão, para o controle de cigarrinhas, moscas-brancas, cochonilhas, entre outros, sendo registrado inicialmente neste país em dezembro de 1983 (Shibuya, 1984).

Seu principal modo de contaminação é por contato direto com o corpo dos insetos. Entretanto, apresenta uma pequena ação sistêmica (Pan \& Chiu, 1989 e Dai et al., 1992), havendo translocação do produto aplicado ao caule de arroz para as folhas, sem entretanto, haver translocação para a parte aérea quando o produto é aplicado junto às raízes (Bei et al., 1996).

\subsubsection{Efeito sobre a fase jovem dos insetos}

$O$ inseticida buprofezin interfere na biossíntese de quitina afetando a formação da nova cutícula (Uchida et al., 1985). Segundo estes autores, ninfas de quinto instar de Nilaparvata lugens (Hemiptera: Delphacidae), tratadas com buprofezin a $50 \mathrm{ppm}$, mostraram anormalidades e dificuldades em se livrar da velha cutícula, chegando a $100 \%$ de mortalidade. Este efeito iniciou após 84 horas do tratamento. A biossintese de $\left[{ }^{4} \mathrm{C}\right]$ quitina sintetizada a partir de $\left[{ }^{14} \mathrm{C}\right]$ glucose, foi inibida em $47 \%$ em ninfas tratadas com $10 \mathrm{ppm}$ de buprofezin, sendo que em mais de $70 \%$, a emergência dos adultos não foi observada.

Larvas de quarto instar de Henosepilachna vigintioctopunctata (Coleoptera: Coccinellidae), tratadas topicamente com $4 \mu \mathrm{g}$ de buprofezin/ inseto, mostraram redução de $74,4 \%$ na biossíntese de quitina. Fazendo-se a imersão de folhas de tomate em uma solução contendo $50 \mathrm{ppm}$ de buprofezin e posteriormente oferecendo às larvas de $H$. vigintioctopunctata, constatou-se 
redução de $42,1 \%$ na biossíntese de quitina a partir de $\mathrm{N}$-acetil-D-[1,6 ${ }^{3} \mathrm{H}$ ]glucosamino (Izawa et al., 1986).

Yarom et al. (1988) concluiram que as $C_{50}$ do inseticida buprofezin sobre ninfas de primeiro e segundo instar de Aonidiella aurantii (Hemiptera: Diaspididae) foram de 0,127 e $0,135 \mathrm{ppm}$, respectivamente. Para ninfas de Saissetia oleae (Hemiptera: Coccidae), também de primeiro e segundo instar, as $\mathrm{CL}_{50}$ obtidas foram de 0,008 e 0,031 ppm de buprofezin, respectivamente.

A sintese de quitina a partir de $\mathrm{N}$-acetil-D-[3H]glucosamino foi fortemente inibida pelo tratamento com buprofezin em ninfas de quinto instar de Nilaparvata lugens (Izawa et al., 1985). Estes autores concluíram que o inseticida interfere na polimerização de UDP-N-acetil-D-glucosamino, visto que não houve inibição na síntese deste composto que é o último precursor da quitina. Este efeito também foi notado nos compostos classificados como benzoilfeniluréias (Verloop \& Ferrel; Hajjar \& Casida e Cohen \& Cassida citados por Izawa et al., 1985), dentre os quais podemos citar: triflumuron, clorfluazuron, teflubenzuron, lufenuron e diflubenzuron.

Não se sabe exatamente o sítio de ação de buprofezin, entretanto, algumas descobertas neste sentido foram feitas. Sabe-se que, durante 0 processo de ecdise, a apólise é promovida pelo aumento no nível de 20hidroxiecdisônio. A multiplicação das células da epiderme e parte da secreção da nova cutícula ocorrem após a apólise sob a influência de alta concentração deste hormônio. Antes da muda propriamente dita, o nível de 20hidroxiecdisônio começa a decrescer, promovendo a ativação de enzimas do fluido da ecdise para a digestão de parte da velha cutícula. Notou-se que, o inseticida buprofezin interfere na degradação do hormônio da muda em ninfas de Nilaparvata lugens, visto que, em insetos tratados, a queda no nível deste hormônio deu-se tardiamente. Tal efeito pode ser atribuído pela inibição da enzima que metaboliza o 20-hidroxiecdisônio. Com isto, o inseticida não afeta qualquer processo até a apólise, mas inibe fortemente os processos posteriores 
como a digestão da velha cutícula e síntese de quitina da nova cutícula (Kobayashi et al., 1989).

Segundo Uchida (1986), ninfas de quinto instar tratadas com buprofezin e que receberam também injeção do hormônio da muda, não morreram durante a ecdise. Isto indica que o ecdisônio apresenta um efeito antagônico sobre 0 inseticida buprofezin e portanto, a ação primária deste produto pode estar relacionada a um distúrbio no metabolismo deste hormônio.

Para Jarvis et al. (1994), a inibição na síntese deste hormônio pelo buprofezin dá-se nos passos iniciais de sua síntese.

De acordo com o trabalho desenvolvido por De Cock \& Degheele (1993), larvas de terceiro instar de Trialeurodes vaporariorum (Hemiptera: Aleyrodidae), não conseguiram completar a ecdise e acabaram morrendo no interior da velha cutícula no momento de mudança para o estágio pupal. A largura da procutícula foi reduzida em $80 \%$ nas larvas tratadas com buprofezin na concentração de 10 ppm. Neste trabalho, ficou claro também que o inseticida interfere na biossíntese da quitina que ocorre somente após a apólise, sendo que, antes deste processo, a síntese deste composto dá-se normalmente. Este efeito retardado sugere novamente que o inseticida apenas apresenta ação após o momento que o nível de 20-hidroxiecdisônio decresceria normalmente, no período entre as mudas do inseto. Este mecanismo não é o mesmo notado para as benzoilfeniluréias, que mostram inibição na biossíntese de quitina mesmo antes da apólise.

A atividade letal do buprofezin é relativamente alta para algumas espécies sendo a $C L_{50}$ de $0,13 \mathrm{ppm}$ para ninfas de primeiro instar (Asai \& Fukada, 1983) e 1,10 ppm para ninfas de quinto instar (Izawa et al., 1985) de Nilaparvata lugens, mantidas em plantas de arroz previamente contaminadas. Mais do que $10 \mathrm{ppm}$ de buprofezin levou a $100 \%$ de mortalidade, com parcial inibição da síntese de quitina. Para concentrações de 10 e 50 ppm, obteve-se 35 e $70 \%$ na inibição da biossíntese deste composto, respectivamente. $\mathrm{Al}_{25}$, ou 
seja, a concentração que causa $25 \%$ de inibição da síntese de quitina, foi de 2,6 ppm (Izawa et al., 1985).

As ninfas de Nilaparvata lugens quando são intoxicadas com buprofezin, morrem na maior parte das vezes, na posição de troca de cutícula, geralmente presa a esta (Asai \& Fukada, 1983) e tornam-se escurecidas e secas, sintoma este semelhante ao observado em Pieris brassicae tratada com diflubenzuron (Uchida et al., 1985). Sintomas parecidos foram observados em larvas de Henosepilachna vigintioctopunctata intoxicadas por buprofezin que mostravam o corpo escurecido e morriam antes de tornarem-se pupas (Izawa et al., 1986).

O inseticida buprofezin não apresenta bom efeito de choque, levando de maneira geral, de 3 a 7 dias para levar ninfas de Nilaparvata lugens a morte (Shibuya, 1984).

Quanto ao efeito residual, Shibuya (1984), constatou que ninfas de terceiro instar de Nilaparvata lugens mostraram alta mortalidade até 40 dias após a aplicação, quando colocadas em contato com plantas de arroz previamente imersas em solução de buprofezin a 250 ppm. Nesta mesma concentração de carbaril, um inseticida carbamato, o efeito residual só foi notado na primeira semana.

Em condições de campo, Hu et al. (1993), verificaram que buprofezin a 400 ppm proporcionou controle sobre Empoasca flavescences na cultura de chá de 92 e 95\%, aos 10 e 15 dias após a aplicação, respectivamente. Lai (1993), em trabalho conduzido na China também em condições de campo, verificou que o inseticida buprofezin mostrou controle de 92 e $97 \%$ sobre Empoasca flavescens e E. pirisuga, após duas semanas e na dosagem de 125 ppm. 


\subsubsection{Efeito sobre a fase adulta dos insetos}

\subsubsection{Importância da prostaglandina no processo de postura}

As prostaglandinas pertencem a classe dos lipídios e ocorrem em mamíferos, aves, insetos, etc, estando muitas vezes ligada a processos reprodutivos (Stanley-Samuelson, 1994a e Stanley-Samuelson \& Pedibhotla, 1996) e tendo como precursor um ácido graxo essencial (Stanley-Samuelson et

al., 1987), o ácido arachidônico, no caso específico da prostaglandina $E_{2}$ (Stanley-Samuelson \& Loher, 1986).

$A$ aplicação exógena de prostaglandina $E_{2}$ em fêmeas virgens de Acheta domesticus (Orthoptera: Gryllidae), uma espécie de grilo, levou ao estímulo da postura indicando que esta substância participa deste processo, sendo entretanto, rapidamente metabolizada, visto que, tal efeito só foi sentido pelas fêmeas no primeiro dia após a aplicação (Destephano \& Brady, 1977).

Efeito semelhante a este foi encontrado por Loher (1979) e StanleySamuelson et al. (1986), trabalhando com outra espécie de grilo, Teleogryllus commodus. Ainda com relação a esta espécie, Ai et al. (1986) concluíram que a prostaglandina $E_{2}$ não interfere na produção de ovos, mas apenas no processo de postura. Neste trabalho concluiu-se também que fêmeas acasaladas que tiveram seus ovários retirados, continuaram o processo de postura dos ovos que já haviam sido gerados.

As substâncias caracterizadas como prostaglandinas podem estar ligadas a outros aspectos da reprodução, pois ocorrem no trato reprodutivo de insetos nos quais esta substância não é responsável pelo estímulo ao processo de postura (Stanley-Samuelson, 1994b).

No trabalho desenvolvido por Destephano \& Brady (1977), concluiu-se que a prostaglandina, bem com a enzima que catalisa sua sintese, estavam presentes nos órgãos reprodutivos dos machos de grilos da espécie Acheta 
domesticus. Entretanto, nas fêmeas virgens não foram encontradas estas substâncias. Analisando-se posteriormente os tecidos dos órgãos reprodutivos provenientes de fêmeas acasaladas, notou-se quantias consideráveis tanto da prostaglandina quanto de sua enzima. Concluiu-se também que, a quantidade de prostaglandina presente nos órgãos reprodutivos das fêmeas acasaladas desta espécie de grilo, não correspondiam somente à quantidade transferida através dos espermatóforos, mas grande parte foi sintetizada no corpo da fêmea, catalisada pela enzima prostaglandina sintetase, previamente transferida pelos machos durante a cópula.

Brenner \& Bernasconi (1989), observaram que os espermatóforos da espécie Triatoma infestans (Hemiptera: Reduviidae), continham grande quantidade de ácido arachidônico, ao passo que nas fêmeas virgens, esta substância estava presente em baixa quantidade nas gônadas. Do mesmo modo, a enzima prostaglandina sintetase estava presente nos espermatóforos de machos e ausente nas gônadas de fêmeas virgens, que passaram a apresentar esta substância somente após 6 horas da cópula. Concluiu-se então que, os machos transferem estas substâncias às fêmeas desta espécie durante a cópula dando início ao processo de síntese da prostaglandina nos órgãos reprodutivos das fêmeas.

No trabalho desenvolvido por Stanley-Samuelson et al. (1983), não foi encontrada a substância prostaglandina $E_{2}$, bem como a enzima que catalisa sua síntese, a prostaglandina sintetase, na espermateca de fêmeas virgens de Teleogryllus commodus. Entretanto, nas fêmeas acasaladas encontrou-se grande quantidade destas substâncias. Além deste órgão analisado, encontrouse também quantia considerável de prostaglandina $E_{2}$ na cabeça de fêmeas virgens, que praticamente dobraram a quantidade em fêmeas acasaladas, além de pequena porção na corda nervosa central de fêmeas virgens, indicando que fêmeas não acasaladas desta espécie sintetizam por si só estas substâncias. Para estes autores, a atividade da prostaglandina encontrada nestes órgãos do sistema nervoso não está aparentemente ligada aos efeitos resultantes tanto da 
prostaglandina quanto da prostaglandina sintetase provenientes dos espermatóforos dos machos durante a cópula. Tais observações sugerem que a prostaglandina esteja ligada a vários outros processos fisiológicos nos insetos e não apenas durante a reprodução. Sugawara (1986) e Ai et al. (1986), concluíram que o fator estimulante da postura em Teleogryllus commodus, a prostaglandina $E_{2}$, exerce seu efeito no processo reprodutivo via sistema nervoso.

Vimos até agora que existem várias espécies de insetos cuja postura é estimulada pelas substâncias genericamente chamadas de prostaglandinas. Entretanto, tal fato não se aplica à todas. Por exemplo, Lange (1984), concluiu que apesar dos machos de Locusta migratoria (Orthoptera: Acrididae) transferirem a enzima prostaglandina sintetase para as fêmeas durante o acasalamento, a prostaglandina não está relacionada a colocação de ovos nesta espécie. O mesmo foi observado por Hagen \& Brady (1982) na espécie Trichoplusia ni (Lepidoptera: Noctuidae), cuja injeção de prostaglandina em fêmeas virgens não desencadeou o processo de postura. Segundo Yamauchi et al. (1997), a prostaglandina também não desencadeia o processo de postura em Bombyx mori (Lepidoptera: Bombycidae), contrariando a hipótese inicialmente proposta por Yamaja-Settya \& Rmaiah (1980). O que estimula a postura nesta espécie é o fluido proveniente das glândulas acessórias dos machos e transferidos às fêmeas durante a cópula.

\subsubsection{Efeito sobre a longevidade e fecundidade}

O composto buprofezin não tem efeito letal sobre adultos de Nilaparvata lugens (Hemiptera: Delphacidae), porém, mostrou redução de 30 a $40 \%$ na longevidade de fêmeas com até 48 horas de emergência nas concentrações de 250 e 1000 ppm em bioensaio de contato residual. Após este período, para fêmeas e machos de qualquer idade, a longevidade não foi afetada (Asai et al., 1985). 
Kanaoka et al. (1996), observaram que ninfas de quinto instar de Nilaparvata lugens que receberam aplicação de buprofezin a $10 \mathrm{ppm}$ e que chegaram a fase adulta, mostraram redução na longevidade de $74 \%$ em relação a testemunha. Além disto, estas fêmeas não colocaram ovos durante toda a vida.

Além de reduzir a longevidade, o inseticida buprofezin pode causar efeitos adversos sobre a postura e eclosão das ninfas provenientes de fêmeas tratadas (Uchida et al., 1987 e Shibuya, 1984). Fêmeas de N. lugens, mantidas em plantas de arroz pulverizadas com 10 e $50 \mathrm{ppm}$ de buprofezin, mostraram redução na postura de 64,6 e $93,5 \%$, respectivamente. Porém, a supressão na postura provocada pelo buprofezin foi completamente revertida pela injeção de prostaglandina $E_{2}$ (Uchida et al., 1987).

Asai et al. (1985) observaram que adultos de Nilaparvata lugens com até 24 horas de emergência, apresentaram redução total da postura quando mantidos em plantas de arroz tratadas com buprofezin a $250 \mathrm{ppm}$. A partir de 24 horas da emergência dos adultos, a redução na postura é pouco pronunciada, entretanto, a eclosão de ninfas provenientes dos adultos mantidos em plantas tratadas a $250 \mathrm{ppm}$ é praticamente nula. Notaram ainda que, os embriões desenvolviam-se normalmente até a fase final, caracterizada pela pigmentação dos olhos, porém, falhavam durante a eclosão.

Fêmeas de $N$. lugens tratadas com buprofezin, apresentaram acumulação irregular de ovos no interior dos ovários, cujo problema foi revertido pela injeção de prostaglandina $E_{2}$. Desta forma, fica claro que o inseticida age sobre a postura desta cigarrinha, sem entretanto, causar anormalidades no crescimento dos oócitos (Uchida et al., 1987), bem como nos ovaríolos (Asai et al., 1985 e Kanaoka et al., 1996). Fato semelhante foi constatado por Yarom et al. (1988), pois notaram que a embriogênese de Saissetia oleae (Hemiptera: Coccidae) também não foi afetada quando fêmeas adultas desta espécie foram expostas ao inseticida buprofezin na concentração de 500 ppm. Por outro lado, notou-se redução na eclosão de ninfas da ordem de 80 e $100 \%$, provenientes 
de fêmeas tratadas previamente com o inseticida buprofezin na concentração de 500 ppm, por 5-7 e 11-12 dias, respectivamente.

A biossintese de prostaglandina $E_{2}$ em Nilaparvata lugens, foi inibida em 49 e $84 \%$, depois que fêmeas desta espécie foram colocadas sobre plantas de arroz previamente tratadas com buprofezin a 10 e $50 \mathrm{ppm}$, respectivamente, (Uchida et al., 1987).

No trabalho desenvolvido por lzawa et al. (1986), fêmeas de Henosepilachna vigintioctopunctata (Coleoptera: Coccinellidae) alimentadas com folhas de tomate imersas em solução a 1000 ppm de buprofezin, não morreram, entretanto, mostraram redução na postura de $40,9 \%$, em relação as fêmeas não tratadas. Tal efeito também foi conseguido fazendo-se a aplicação de aspirina (Izawa et al., 1986), um composto já conhecido como inibidor da biossíntese de prostaglandina $\mathrm{E}_{2}$ (Wakayama et al., 1986 e Stanley-Samuelson \& Pedibhotla, 1996). Novamente, a inibição da postura foi revertida em casais tratados com buprofezin, pela injeção de prostaglandina $E_{2}$, reforçando a idéia de que a redução na postura decorre da inibição deste composto.

Nenhum outro inseticida regulador de crescimento mostrou interferência na biossíntese de prostaglandina $E_{2}$ nos insetos (Izawa et al., 1986 e Uchida et al. 1987).

De acordo com Uchida et al. (1986) o hormônio da ecdise, 20hidroxiecdisônio, desempenha importante papel na ovulação e na estimulação de postura em Nilaparvata lugens, assim como a prostaglandina $E_{2}$, pois adultos tratados com buprofezin e que receberam injeção de 20hidroxiecdisônio mostraram posturas normais, ao passo que, adultos que receberam só aplicação de buprofezin, mostraram redução na postura de $80 \%$. Como já comentado anteriormente, isto indica que o ecdisônio apresenta um efeito antagônico sobre o inseticida buprofezin e portanto, a ação primária deste produto pode estar relacionada a um distúrbio no metabolismo deste hormônio.

Segundo Yasui et al. (1987), adultos de Trialeurodes vaporariorum (Hemiptera: Aleyrodidae), com 0-24 horas de idade, mantidos em folhas de 
tomate tratadas com 50 a 1000 ppm de buprofezin, mostraram redução na postura entre 60 e $70 \%$. Tal efeito não foi conseguido quando utilizou-se adultos com 48 a 72 horas de idade.

A eclosão de ninfas desta mesma espécie de mosca-branca não foi suprimida nas posturas realizadas entre 0 e 6 horas após a colocação dos adultos em contato com folhas de tomate tratadas com buprofezin. Porém, ovos colocados entre 6 e 24 horas após o contato dos adultos com folhas de tomate pulverizadas com $250 \mathrm{ppm}$ de buprofezin, tiveram eclosão de apenas $14,1 \%$, quando comparado a $99,2 \%$ de eclosão das ninfas no tratamento testemunha. O córion dos ovos tratados tornaram-se escurecidos, evidenciando a fertilização e desenvolvimento embriônico, sendo a morte constatada durante a eclosão (Yasui et al., 1987).

Para que o produto buprofezin mostrasse redução na eclosão das ninfas de Trialeurodes vaporariorum, foi necessário o contato constante pelos insetos com o inseticida, visto que, adultos mantidos em folhas tratadas com 100 ppm por 24 horas e transferidos para folhas não tratadas, mostraram redução significativa na eclosão somente nos ovos colocados de 0 a 24 horas após a retirada dos adultos do contato com folhas contaminadas (Yasui et al., 1987).

Tal fato também é verdadeiro ao verificar o efeito de buprofezin sobre a fecundidade de Bemisia tabaci. Adultos desta espécie foram mantidos por 48 horas em contato com plantas de algodão pulverizadas com buprofezin em várias concentrações e depois colocados em plantas não tratadas. Notou-se que não houve redução no número de ovos depositados pelas fêmeas após a transferência para as plantas que não receberam o produto. Apesar disto, houve redução de $66 \%$ na eclosão de ninfas na concentração de 125 ppm. A eclosão só foi totalmente prejudicada quando avaliou-se ovos provenientes de adultos que foram mantidos durante todo o tempo em contato com plantas de algodão contaminadas com buprofezin a $62,5 \mathrm{ppm}$, por pelo menos 24 horas (Ishaaya et al., 1988). Quanto ao efeito residual, constatou-se redução de $100 \%$ na emergência de adultos provenientes do desenvolvimento de ovos colocados 
por casais que foram mantidos por 48 horas em plantas de tomate, que haviam sido pulverizadas com buprofezin na concentração de 125 ppm há 26 dias.

Trabalhando com esta mesma espécie de mosca branca, Beevi \& Balasubramanian (1991), constataram que a longevidade de fêmeas e machos mantidas em plantas de algodão tratadas com buprofezin a $1000 \mathrm{ppm}$ foi reduzida em 31 e $29 \%$, respectivamente. Quanto ao total de ovos colocados por fêmea, bem como a freqüência de postura (ovos/fêmea/dia), o tratamento a 1000 ppm de buprofezin causou redução de 59 e $41 \%$, respectivamente, quando comparado a testemunha. Analisando os ovos colocados pelas fêmeas tratadas com o inseticida na concentração de $250 \mathrm{ppm}$, concluiu-se que a eclosão foi reduzida em $85 \%$ quando comparado a testemunha. Notou-se também que, o desenvolvimento embriônico deu-se normalmente, entretanto, a eclosão de ninfas foi suprimida em $97 \%$ em função do efeito inseticida.

\subsubsection{Seletividade}

Característica marcante dos inseticidas do grupo dos reguladores de crescimento dos insetos e em especial de buprofezin é a alta especificidade quanto ao alvo biológico e consequentemente alta seletividade aos inimigos naturais. No trabalho desenvolvido por Shibuya (1984), o inseticida buprofezin aplicado diretamente sobre formas jovens de aranhas da espécie Lycosa pseudoannulata na dose de $0,75 \mathrm{~kg}$ i.a./ha, não mostrou qualquer efeito letal sobre esta espécie. Já o inseticida carbamato carbofuran, aplicado nesta mesma dose, mostrou $93 \%$ de mortalidade sobre as formas jovens desta aranha.

Em estudos de seletividade realizados por Carvalho et al. (1994a), o produto buprofezin aplicado diretamente sobre adultos de Ceraeochrysa cubana (Hagen) (Neuroptera: Chrysopidae), não causou qualquer efeito direto sobre esta fase do inseto. Também não afetou o número médio de ovos colocados durante 30 dias pelas fêmeas tratadas, além de não causar qualquer efeito 
adverso sobre a viabilidade destes. Devido a estas características, o produto buprofezin foi classificado como altamente seletivo para este inimigo natural.

Estudando outra espécie de crisopídeo, Velloso et al. (1997), demonstraram que o inseticida buprofezin na concentração de 750 ppm, não causou qualquer efeito adverso quando aplicado diretamente sobre ovos e larvas de segundo instar de Chrysoperla externa. Em contato residual, o inseticida também não afetou negativamente a fase larval desta espécie nesta concentração. Em função disto, o composto buprofezin foi considerado inócuo a este predador.

Gravena et al. (1992), também notaram que o inseticida buprofezin a 1000 e 2000 ppm, aplicado em plantas de laranja em condições de campo, mostrou baixa toxicidade às larvas de predadores da Família Chrysopidae, sem designar a espécie estudada.

Carvalho et al. (1994b), constataram que buprofezin, aplicado sobre ovos de Anagasta kuheniella na concentração de 125 ppm, não mostrou efeitos negativos sobre o número de ovos parasitados, razão sexual, sobrevivência $e$ longevidade dos descendentes de Trichogramma pretiosum (Hymenoptera: Trichogrammatidae).

Segundo Mendel et al. (1994), o inseticida buprofezin na concentração de $125 \mathrm{ppm}$ apresentou alta seletividade aos seguintes inimigos naturais: Comperiella bifasciata e Encyrtus infelix (Hymenoptera: Encyrtidae), Elatophilus hebraicus (Hemiptera: Anthocoridae) e Crypthochaetum iceryae (Diptera: Cryptochaetidae). Por outro lado, não mostrou-se seletivo aos coccinelídeos, Rodolia cardinalis e Chilocorus bipustulatus, quando larvas destas espécies foram alimentadas com as cochonilhas Icerya purchasi (Hemiptera: Margarodidae) e Aonidiella aurantii (Hemiptera: Diaspididae), respectivamente, previamente contaminadas com o inseticida a $125 \mathrm{ppm}$.

Entretanto, nem todos os coccinelídeos são prejudicados pelo inseticida buprofezin. Segundo Castañer \& Garrido (1995), o contato residual de adultos da espécie Cryptolaemus montrouzieri, sobre uma superfície tratada com 
buprofezin a 250 ppm, não causou mortalidade significativa e não interferiu negativamente na postura desta espécie. Para Gravena et al. (1992), a população de larvas e adultos de Pentilia egena (Coleoptera: Coccinellidae) sobre plantas de laranja não diferiu do tratamento testemunha, quando o inseticida buprofezin foi pulverizado em condições de campo a 1000 e 2000 ppm.

Larvas de Cales noacki (Hymenoptera, Aphelinidae), uma espécie parasita de Aleurothrix floccosus (Hemiptera: Aleyrodidae), mostraram apenas $10 \%$ de mortalidade quando colocadas em contato com folhas de laranjeira tratadas com buprofezin a $250 \mathrm{ppm}$. Ninfas desta mesma espécie, mostraram apenas $5,4 \%$ de mortalidade quando tratadas com esta concentração. A emergência do parasitóide que desenvolveu-se sobre formas jovens de $A$. floccosus tratado com buprofezin a $250 \mathrm{ppm}$, foi de $92,2 \%$, quando comparado a $96,7 \%$ do tratamento testemunha. Ainda neste trabalho, concluiu-se que o inseticida buprofezin não afetou negativamente o número de descendentes provenientes de ninfas tratadas com este produto (Garrido et al., 1984). De acordo com estes mesmos autores, a concentração de 250 ppm de buprofezin não levou a mortalidade de ninfas de Encarsia formosa (Hymenoptera: Aphelinidae), uma espécie parasita de Trialeurodes vaporariorum. Não houve redução na porcentagem de emergência de adultos deste parasitóide desenvolvidos em formas jovens de $T$. vaporariorum tratadas com buprofezin a 250 ppm.

Resultados semelhantes a estes foram obtidos por Castañer \& Garrido (1995) com esta mesma espécie de parasitóide, só que em um bioensaio de contato residual. Neste caso, o inseticida buprofezin a 250 ppm não causou mortalidade significativa de adultos do parasitóide, além de não interferir negativamente no parasitismo das fêmeas sobre Trialeurodes vaporariorum, quando mantidas em contato com uma superfície tratada com o inseticida. Neste mesmo bioensaio, porém avaliando-se adultos da espécie Lysiphlebus testaceipes (Hymenoptera: Aphidiidae), notou-se que a mortalidade adultos, 
bem como a redução do parasitismo de fêmeas, foram de apenas 25 e $10 \%$, respectivamente.

Segundo Hayashi (1996), o inseticida buprofezin não causou mortalidade de pupas e adultos de Encarsia formosa, quando estas fases do inimigo natural foram submetidos a imersão e contato com folhas contaminadas com 0 inseticida.

Adultos da espécie de parasitóide Encarsia luteola (Hymenoptera: Aphelinidae), tiveram a emergência reduzida em $56 \%$, quando ninfas de Bemisia tabaci parasitadas pela fase larval deste inimigo natural foram imersas em solução de buprofezin a $20 \mathrm{ppm}$. Fazendo-se o tratamento de ninfas de $B$. tabaci, contendo pupas deste parasitóide em seu interior, com o inseticida buprofezin a 1000 ppm, notou-se redução na eclosão de adultos de $77 \%$. Entretanto, o parasitismo não foi afetado pelo inseticida e notou-se até um incremento de $40 \%$ quando tratou-se diretamente os adultos com $100 \mathrm{ppm}$ de buprofezin e $30 \%$ de incremento quando os adultos emergiram a partir de ninfas de mosca branca tratadas com $20 \mathrm{ppm}$ de buprofezin contendo ovos do parasitóide em seu interior (Gerling \& Sinai, 1994).

Segundo Jones et al. (1998), o inseticida buprofezin na concentração de 110 ppm, reduziu consideravelmente a emergência de adultos do parasitóide Eretmocerus tejanus (Hymenoptera: Aphelinidae), quando aplicado sobre larvas de Bemisia argentifolii aos cinco dias após o parasitismo. Por outro lado, quando a pulverização das larvas de mosca branca deu-se aos 14 dias após o parasitismo, não foi observada redução na emergência de adultos tanto de Eretmocerus tejanus, como de E. mundus. 


\section{MATERIAL E MÉTODOS}

O trabalho foi conduzido no Departamento de Entomologia, Fitopatologia e Zoologia Agrícola, da Escola Superior de Agricultura "Luiz de Queiroz", em Piracicaba, Estado de São Paulo, durante o período de Junho de 1998 a Abril de 1999.

As soluções do inseticida buprofezin utilizadas nos bioensaios, foram preparadas a partir do produto comercial Applaud $250^{\circledR}$, cuja concentração do ingrediente ativo é de $250 \mathrm{~g} / \mathrm{kg}$ e apresentado na formulação pó molhável.

\subsection{Identificação da espécie de cigarrinha}

Antes de dar início aos experimentos, alguns exemplares das cigarrinhas da criação mantida em laboratório, foram identificadas como pertencentes a espécie Empoasca kraemeri, pela Eng. Agr. MSc. Ranyse Barbosa Querino da Silva, aluna de Doutorado do Curso de Pós-Graduação em Entomologia da ESALQ/USP.

\subsection{Criação de Empoasca kraemeri}

As cigarrinhas foram criadas em plantas de feijão do cultivar IACCarioca, em vasos plásticos e mantidas em gaiolas de criação com armação de madeira, cujas dimensões eram: $0,5 \mathrm{~m}$ de altura $\times 0,3 \mathrm{~m}$ de largura $\times 0,3 \mathrm{~m}$ de fundo e revestida em todos os lados, bem como na porção superior, por uma 
tela de tecido (voil). As gaiolas eram mantidas em casa de vegetação, a temperatura de $25 \pm 5^{\circ} \mathrm{C}$ e umidade relativa entre 70 e $90 \%$.

Os primeiros representantes de Empoasca kraemeri, aproximadamente 100 insetos, foram obtidos a partir de folhas de feijão, coletadas em uma cultura do cultivar IAC-Carioca, no Setor de Entomologia da ESALQ/USP. Após a coleta, foi feita a retirada de todos os indivíduos (ninfas e adultos) presentes no material, o qual foi acondicionado em laboratório, colocando-se o pecíolo imerso na água para evitar o ressecamento. À medida que as ninfas eclodiam era feita a transferência dos indivíduos para as gaiolas de criação.

A cada quinze dias, novas ninfas eram colocadas na criação para que a população não sofresse problemas de cruzamentos constantes entre parentes próximos, evitando problemas de endogamia que pudesse influir negativamente na sobrevivência e comportamento dos insetos utilizados nos experimentos.

Diariamente as plantas eram irrigadas e a cada duas semanas eram colocadas novas plantas e retiradas as que estavam debilitadas.

\subsection{Efeito de buprofezin sobre ninfas de Empoasca kraemeri em bioensaio de contato residual}

Procurou-se neste bioensaio verificar a ação do inseticida buprofezin sobre a forma jovem de Empoasca kraemeri. Para isto, algumas folhas de feijão da criação foram retiradas, tomando-se o cuidado para deixá-las isentas de ninfas e adultos do inseto, contando apenas com a presença de ovos. Estas folhas eram mantidas com o pecíolo imerso na água e entre períodos máximos de 12 horas eram feitas vistorias a fim de verificar a eclosão de ninfas, que eram anestesiadas utilizando-se gás carbônico por alguns segundos e transferidas com auxilio de um fino pincel, sobre folíolos de feijão previamente preparados com os respectivos tratamentos.

Adotou-se o delineamento experimental inteiramente casualizado, com 8 tratamentos e 6 repetições, sendo cada parcela constituida por 5 ninfas de 
primeiro instar, as quais foram colocadas sobre folíolos previamente tratados com o inseticida buprofezin. Após vários testes preliminares, chegou-se nas seguintes concentrações definitivas: $0 ; 0,063 ; 0,083 ; 0,096 ; 0,111 ; 0,198 ; 0,351$ e 0,625 ppm de buprofezin.

Os folíolos foram imersos nas soluções inseticidas durante 20 segundos, deixados para secar ao ar livre e mantidos em placas de petri com o pecíolo envolto por algodão umedecido em água destilada (Figura 1).

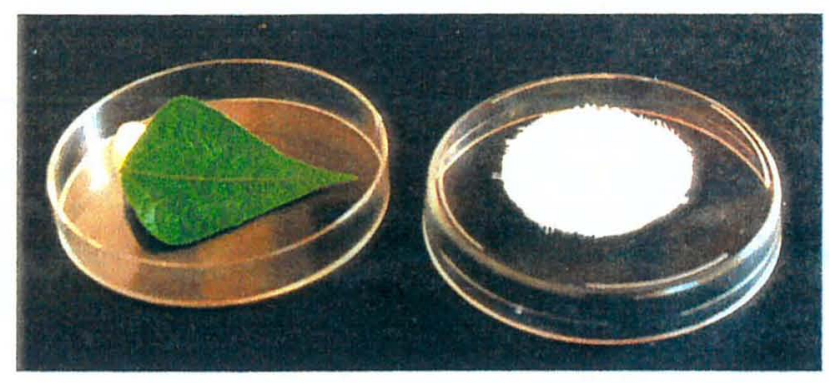

Figura 1. Placas de petri aberta $(A)$ e fechada $(B)$ utilizadas na condução dos ensaios de mortalidade com ninfas de $E$. kraemeri, em bioensaio de tratamento com buprofezin através do contato residual.

As placas de petri eram mantidas em câmara climatizada, à temperatura de $25 \pm 0,5^{\circ} \mathrm{C}$, umidade relativa de $80 \pm 10 \%$ e fotofase de 12 horas.

A mortalidade de ninfas foi avaliada dois dias após a infestação. Este tempo foi suficiente para permitir pelo menos uma ecdise e avaliar o efeito do inseticida.

Os dados de mortalidade obtidos adequaram-se a distribuição betabinomial e através da ligação logística, obteve-se uma equação capaz de estimar a mortalidade de ninfas em função da contaminação por uma concentração do inseticida buprofezin via contato residual. 


\subsection{Efeito de buprofezin sobre adultos de Empoasca kraemeri}

\subsubsection{Contaminação de casais em diferentes concentrações em bioensaio de contato residual}

A finalidade deste bioensaio foi verificar qual o efeito do inseticida buprofezin sobre adultos de Empoasca kraemeri, mantidos durante toda a vida em contato com plantas de feijão contaminadas com o produto. Para isto, casais virgens e recém emergidos, foram colocados em contato com plantas de feijão previamente imersas em soluções de buprofezin.

Para a obtenção de casais virgens, ninfas de quinto instar foram transferidas isoladamente para copos plásticos transparentes $(300 \mathrm{ml})$, contendo uma plântula de feijão. Após a emergência, os adultos eram coletados por meio de tubos de vidro (Figura 2), sendo observados em um microscópio estereoscópio de 10 aumentos, a fim de determinar o sexo através da presença ou ausência do ovipositor.

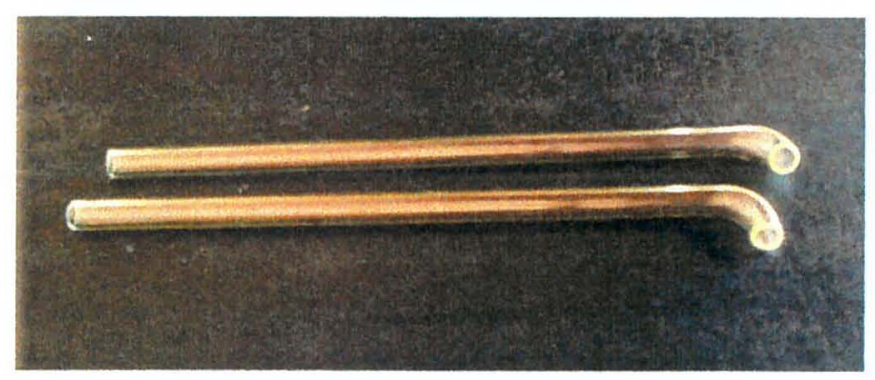

Figura 2. Tubos de vidro utilizados para a transferência de adultos de $E$. kraemeri.

Adotou-se o delineamento experimental inteiramente casualizado com 3 tratamentos: 0,10 e $50 \mathrm{ppm}$ de buprofezin e 4 repetições. Cada parcela era constituída por 4 casais recém emergidos (0-12 horas de idade), colocados 
sobre uma planta de feijão apresentando 2 trifólios e previamente imersas na respectiva solução inseticida durante 20 segundos e deixadas para secar ao ar livre. Posteriormente, foram colocadas dentro de gaiolas formadas por potes plásticos transparentes com volume de 1 litro (Figura 3), apresentando em sua porção superior abertura tampada com "voil" para permitir boa ventilação. As gaiolas eram mantidas em laboratório, à temperatura de $25 \pm 1^{\circ} \mathrm{C}$ e umidade relativa entre 70 e $90 \%$.
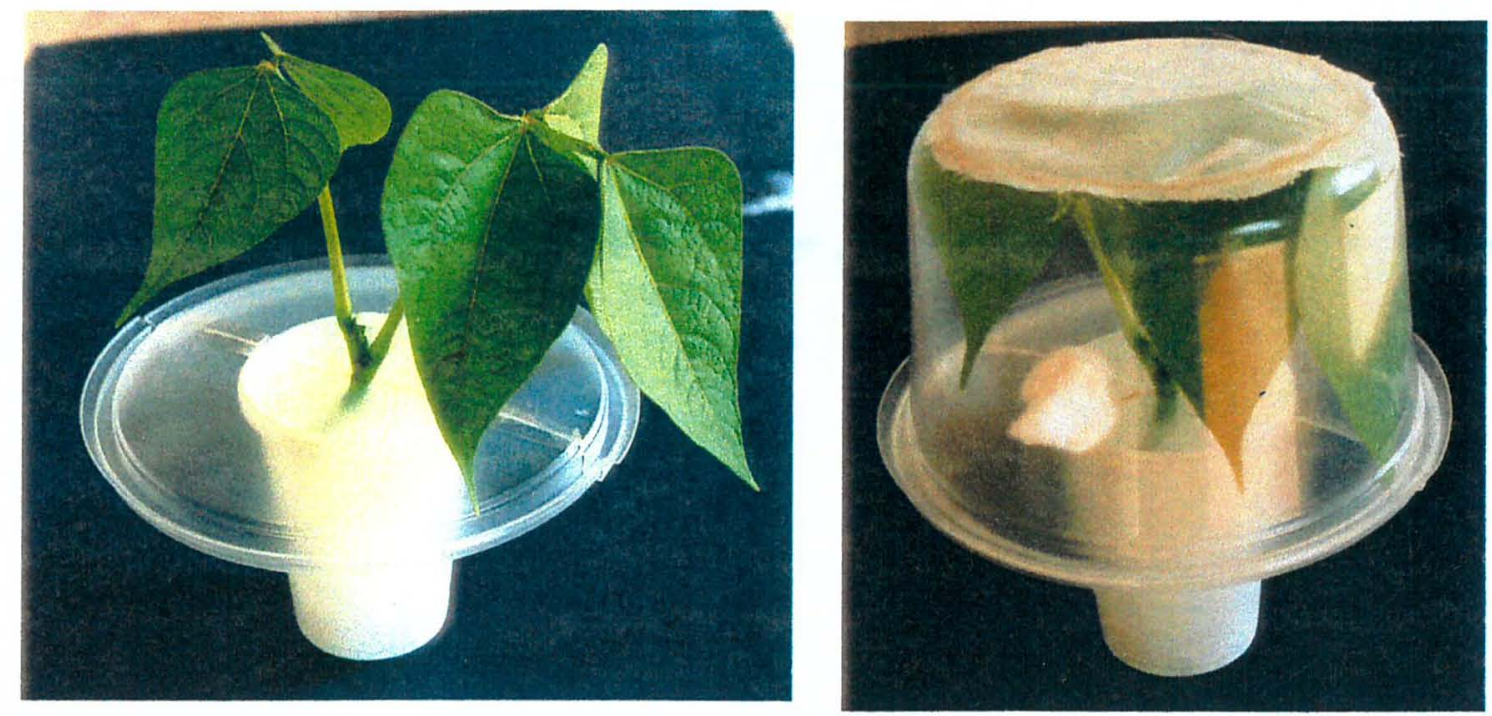

Figura 3. Planta de feijão em solução nutritiva $(A)$ e pote plástico (B) utilizados na condução de ensaios de contaminação com buprofezin via contato residual com adultos de E. kraemeri.

Decorridos cinco dias da permanência das cigarrinhas em contato com as plantas, estas eram transferidas novamente para plantas recém tratadas para a continuidade do processo de postura por mais cinco dias e assim sucessivamente, até que todos os representantes estivessem mortos.

Durante a transferência dos insetos adultos, os potes plásticos eram abertos no interior de uma câmara de manipulação formada por paredes laterais de madeira de dimensões: $0,8 \mathrm{~m}$ de largura $\times 1,0 \mathrm{~m}$ de altura $\times 0,8 \mathrm{~m}$ de 
fundo, sendo a parte interna toda pintada de preto. A parte posterior da câmara era composta por uma parede plástica branca semitransparente com $3 \mathrm{~mm}$ de espessura e iluminada por fora por meio de lâmpadas fluorescentes. Na frente da câmara havia uma cortina de tecido que permitia o acesso ao seu interior, mas impedia a fuga dos insetos, os quais dirigiam-se para o fundo branco iluminado, sendo coletados através de um pequeno tubo de vidro (Figura 2) utilizado para a transferência em outra gaiola que continha uma planta de feijão previamente tratada, como explicado anteriormente.

As plantas retiradas eram clareadas de acordo com o método de Carlson \& Hibbs (1962), em solução fervente de lactofenol durante 3 minutos, findo os quais, era feita a contagem dos ovos com auxílio de um microscópio estereoscópio com aumento de 10 vezes. As folhas, peciolos e caules "clareados" eram colocados em placas de petri contendo água e iluminados por baixo para que o contorno dos ovos tornassem visíveis. Convém salientar que, apesar deste método ser bastante eficiente no clareamento de folhas $e$ visualização dos ovos, apresenta um inconveniente bastante sério quanto a emissão de fumaça tóxica, exigindo o manuseio em câmara de manipulação adequada para permitir a retirada da fumaça e a utilização constante de máscara para evitar inalação de gases tóxicos.

Avaliou-se a longevidade dos indivíduos, o número de ovos colocados, bem como o ritmo de postura das fêmeas nos diferentes tratamentos.

Os dados de longevidade foram transformados segundo a fórmula $L O G_{10}$. Os dados de postura e ritmo de postura não exigiram transformação. Após os devidos cálculos, os dados foram submetidos a análise da variância e as médias comparadas pelo teste de Tukey a $5 \%$ de significância. 


\subsubsection{Contaminação de machos ou fêmeas em bioensaio de contato residual}

Neste bioensaio procurou-se verificar em qual sexo 0 inseticida buprofezin causaria maiores efeitos. Para isto, foram isolados 4 insetos do mesmo sexo por parcela, ora machos, ora fêmeas e colocados isoladamente por 30 segundos em contato com um tubo de vidro de dimensões $(8 \mathrm{~cm}$ de altura $\times 2 \mathrm{~cm}$ de diâmetro), cuja superfície interna fora previamente contaminada com uma solução a $1000 \mathrm{ppm}$ de buprofezin e seco à sombra. Posteriormente, os insetos foram transferidos para potes plásticos (Figura 3) onde haviam 4 indivíduos do sexo oposto que não haviam sido contaminados. Nota-se que, neste caso as plantas não apresentavam-se contaminadas com 0 inseticida. Os potes plásticos eram mantidos no laboratório a temperatura de 25 $\pm 1^{\circ} \mathrm{C}$ e umidade relativa entre 70 e $90 \%$.

Para a obtenção de indivíduos virgens adotou-se o mesmo procedimento descrito no item 3.4.1.

Adotou-se o delineamento experimental inteiramente casualizado com 3 tratamentos: fêmeas tratadas, machos tratados e testemunha e 4 repetições. Cada parcela era formada por 4 casais recém emergidos (0-12 horas de idade) colocados sobre uma planta de feijão como descrito no item 3.4.1. O processo de transferência dos indivíduos para novas plantas ( 5 em 5 dias), bem como o clareamento das folhas para visualização dos ovos também foi o mesmo já descrito no item 3.4.1.

Avaliou-se a longevidade dos indivíduos, o número de ovos colocados, bem como o ritmo de postura das fêmeas nos diferentes tratamentos.

Os dados de longevidade foram transformados segundo a raiz quadrada, submetidos a análise de variância e as médias comparadas pelo teste de Tukey a $5 \%$ de significância. 
Não foi necessário fazer a transformação dos dados de postura e ritmo de postura, sendo então, submetidos a análise de variância e as médias comparadas pelo teste de Tukey a $5 \%$ de significância. 


\section{RESULTADOS E DISCUSSÃO}

\subsection{Efeito de buprofezin sobre ninfas de Empoasca kraemeri em bioensaio de contato residual}

Os dados originais de mortalidade de ninfas foram transformados usando a fórmula para correção proposta por Abbott (1925), visto que, houve mortalidade no tratamento testemunha da ordem de $3,3 \%$, obtendo-se assim, a mortalidade corrigida.

Foi notado claramente aumento no número de respostas quanto a mortalidade de ninfas, em função do incremento na concentração de buprofezin no bioensaio de contato residual (Tabela 1 e Figura 4).

Dados de proporção, como é o caso da porcentagem de ninfas mortas em relação ao total de ninfas testadas para cada concentração, geralmente apresentam distribuição binomial (Hinde \& Demétrio, 1998). Entretanto, no caso em questão, verificou-se que a distribuição mais adequada para a proporção de ninfas mortas seria a beta-binomial, pois este modelo leva em consideração a alta variabilidade observada em alguns experimentos (Vieira, 1998).

Isto ocorre, pois os dados apresentam maior variação do que seria esperado pelo ajuste binomial. Esta maior variabilidade é chamada de superdispersão, sendo designada para este caso específico, variação extrabinomial (Demétrio, 1994).

O fenômeno de superdispersão significa que, a variância observada da variável resposta $Y$ excede a variância esperada para a distribuição em estudo (Demétrio, 1994). 
Tabela 1. Mortalidade de ninfas de primeiro instar de E. kraemeri aos 2 dias após o tratamento, em função da exposição em diferentes concentrações de buprofezin, em bioensaio de contato residual.

\begin{tabular}{ccccc}
\hline $\begin{array}{c}\text { Concentração } \\
(\mathrm{ppm})\end{array}$ & $\begin{array}{c}\text { Número de } \\
\text { Indivíduos } \\
\text { Testados }\end{array}$ & $\begin{array}{c}\text { Número de } \\
\text { Mortos }\end{array}$ & $\begin{array}{c}\text { \% Mortalidade } \\
\text { Original }\end{array}$ & $\begin{array}{c}\text { \% Mortalidade } \\
\text { Corrigida* }\end{array}$ \\
\hline 0 & 50 & 2 & 3,3 & - \\
0,0625 & 30 & 4 & 13,3 & 10,3 \\
0,0833 & 30 & 8 & 26,3 & 23,7 \\
0,0962 & 36 & 16 & 48,4 & 46,6 \\
0,1111 & 30 & 19 & 63,3 & 62,1 \\
0,1976 & 30 & 21 & 70,0 & 69,0 \\
0,3510 & 30 & 29 & 96,7 & 96,6 \\
0,6250 & 30 & 28 & 93,3 & 93,1 \\
\hline TOTAL & 266 & \multicolumn{4}{c}{} \\
\hline
\end{tabular}

* Mortalidade corrigida segundo a fórmula de Abbott (1925).

Uma maneira de verificar se o modelo está bem ajustado é utilizar o gráfico chamado "Half-normal Plot". Este gráfico é obtido, plotando-se os valores absolutos ordenados de uma medida de diagnóstico adequada contra os "Half-normal Scores" (as estatísticas de ordem esperadas). Um modelo adequado apresenta um padrão onde os pontos se distribuem aproximadamente em torno de uma reta. Para fornecer uma base de comparação e diminuir a subjetividade desta análise, o gráfico é aumentado com envelopes de simulação, correspondentes aos "Half-normal Plots" de amostras simuladas através do modelo assumido e dos valores dos parâmetros estimados. Se o modelo é adequado, é esperado que os valores observados se distribuam dentro do envelope simulado (Vieira, 1998). 
Os gráficos dose $x$ mortalidade, normalmente apresentam curvas sigmóides. A fim de transformar estas curvas em retas, para que técnicas de regressão linear simples possam ser usadas para a estimação inicial dos parâmetros (Zocchi, 1993), foi feita a transformação "logit". Esta transformação geralmente leva a parâmetros ajustados muito próximos do ajuste feito usando a transformação "probit", com a vantagem de que o "logit" possibilita maiores facilidades de cálculos (Zocchi,1993).

Usando-se a ligação logística, tem-se que a proporção estimada de mortalidade $\pi(x)$ a uma certa concentração $x$ do produto, é dada por:

$$
\pi(x)=\frac{e^{\left[17,52+4,477 \log \left(\frac{x}{1000}+0,00001\right)\right]}}{1+e^{\left[17,52+4,477 \log \left(\frac{x}{1000}+0,00001\right)\right]}}
$$

e que:

$$
C L_{50}=0,1121 \mathrm{ppm}
$$

Intervalo de $95 \%$ de Confiança: $I C\left(C L_{50}\right)=[0,0856 ; 0,1459]$

Foi notado através deste bioensaio conduzido em condições controladas de laboratório que, o inseticida buprofezin apresentou alta toxicidade às ninfas de primeiro instar de Empoasca kraemeri, com $\mathrm{CL}_{50}$ de $0,112 \mathrm{ppm}$. Este poderoso efeito inseticida também foi notado em outra espécie de cigarrinha, Nilaparvata lugens, uma importante praga do arroz na Ásia, com $\mathrm{CL}_{50}$ de 0,13 e $1,10 \mathrm{ppm}$ para ninfas de primeiro (Asai \& Fukada, 1983) e quinto instares (Izawa et al., 1985), respectivamente.

Alta toxicidade de buprofezin também foi notada sobre representantes de outra família da ordem Hemiptera. Yarom et al. (1988) constataram $\mathrm{CL}_{50}$ de 0,127 e 0,008 ppm sobre ninfas de primeiro instar de Aonidiella aurantii (Hemiptera: Diaspididae) e Saissetia oleae (Hemiptera: Diaspididae), respectivamente. 


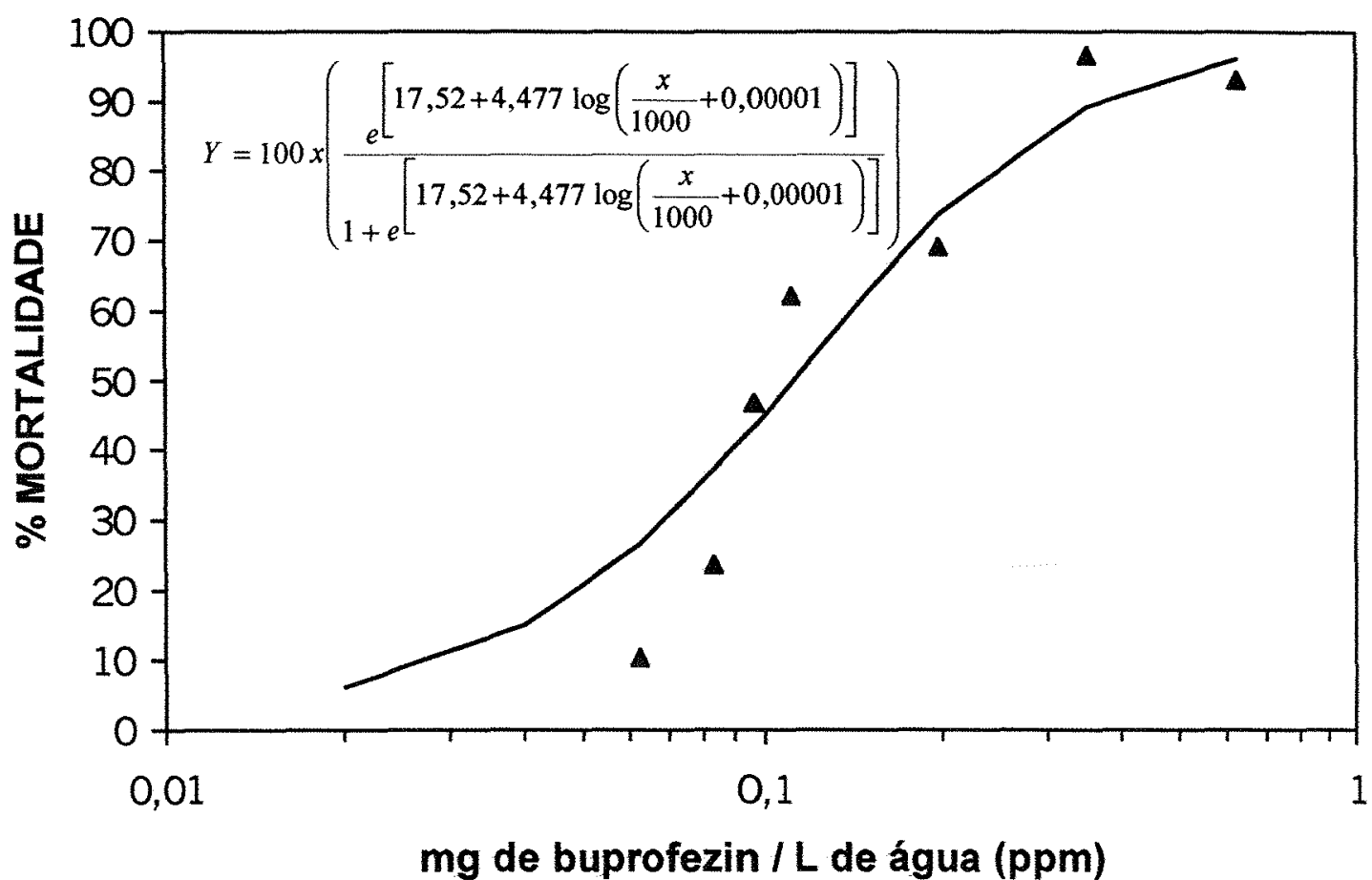

MORTALIDADE OBSERVADA CORRIGIDA MORTALIDADE ESTIMADA

Figura 4. Mortalidade de ninfas de primeiro instar de $E$. kraemeri aos 2 dias após o tratamento, em função da exposição em diferentes concentrações de buprofezin, em bioensaio de contato residual.

Algumas ninfas de cigarrinha verde morreram no interior da velha cutícula, sem conseguirem romper parcialmente a cutícula durante a ecdise. Notou-se também com bastante freqüência que, algumas ninfas conseguiam romper $e$ desprender-se parcialmente da velha cutícula, entretanto, permaneciam presas por alguma estrutura, em geral pelas pernas, à velha exúvia e acabavam morrendo na posição de troca de cutícula, como já observado por Asai \& Fukada (1983), para a espécie Nilaparvata lugens.

Em função dos resultados obtidos tornam-se promissoras pesquisas de campo visando o controle da fase jovem de Empoasca kraemeri nas culturas onde a praga causa prejuízos. 


\subsection{Efeito de buprofezin sobre adultos de Empoasca kraemeri}

\subsubsection{Contaminação de casais em diferentes con centrações em bioensaio de contato residual}

\subsubsection{Efeito sobre a longevidade}

As informações disponíveis na literatura sobre a longevidade de Empoasca kraemeri em condições de laboratório são bastante variadas. Tal fato justifica-se pelas diferentes condições em que cada trabalho foi conduzido, além dos fatores relacionados a variabilidade do inseto em si para cada região de coleta e estudo. De maneira geral, os trabalhos mostram que as fêmeas vivem mais do que os machos, porém, ambos apresentam grande amplitude quanto a longevidade (Segnini \& Montagne, 1986b; Wilde et al., 1976 e Leite Filho \& Ramalho, 1979).

Foi constatado neste bioensaio que as fêmeas e os machos do tratamento testemunha alcançaram longevidade média de 45,7 e 27,0 dias, respectivamente. Apesar desta grande diferença, os dados não apresentaram diferenças estatísticas significativas, devido a grande variabilidade no tempo de sobrevivência dos insetos dentro de cada sexo (Tabela 2 e Figura 5).

Apesar de não ser inicialmente esperado, notou-se que no tratamento em que as plantas haviam sido previamente imersas em solução de buprofezin a 10 ppm, a longevidade média de fêmeas e machos foi de 17,5 e 15,9 dias, respectivamente. Valores parecidos com estes foram observados no tratamento utilizando-se plantas tratadas a 50 ppm, em que machos e fêmeas viveram em média 15,9 e 13,9 dias, respectivamente. Para estes dois tratamentos também não foram observadas diferenças estatísticas significativas entre a longevidade de fêmeas e machos (Tabela 2 e Figura 5). 
Tabela 2. Longevidade média em dias para fêmeas e machos adultos de $E$. kraemeri, em função da exposição em diferentes concentrações de buprofezin, em bioensaio de contato residual.

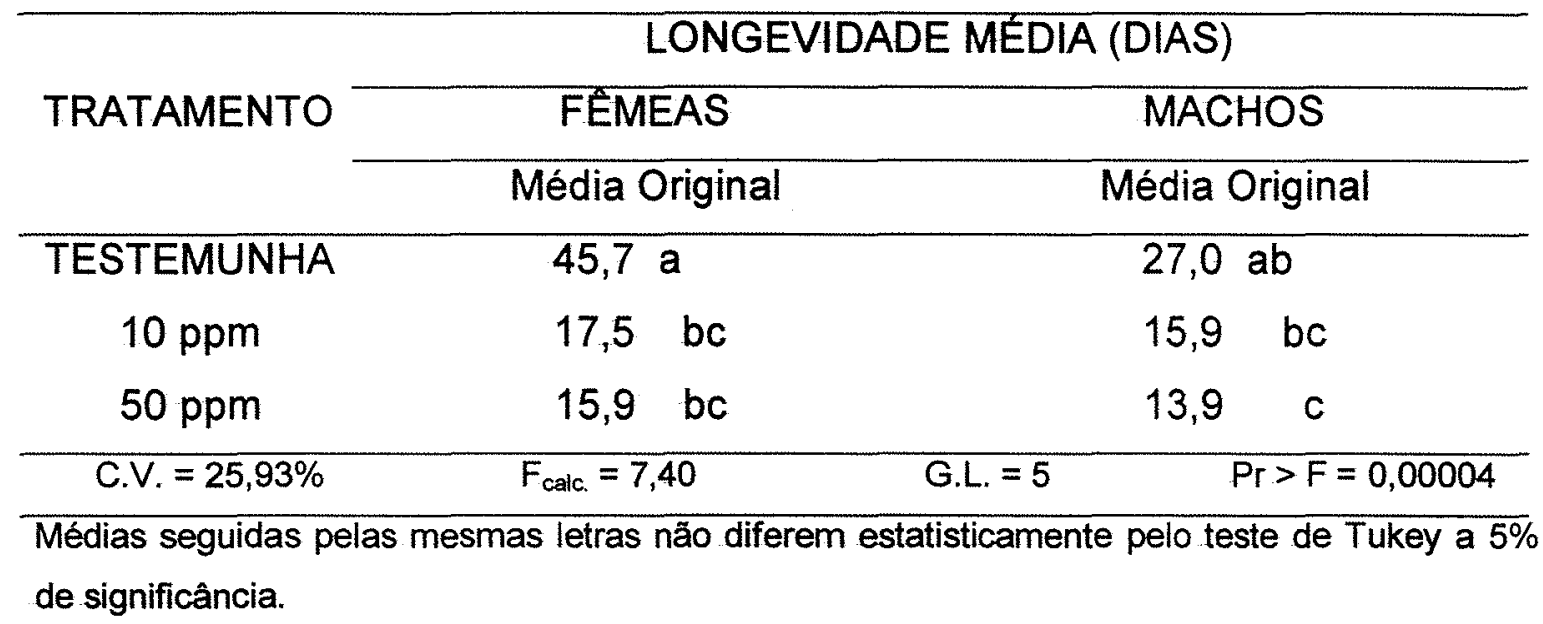

As fêmeas mantidas em plantas de feijão previamente tratadas com buprofezin a 10 e 50 ppm, apresentaram redução na longevidade de 62 e 65\%, respectivamente. Quanto aos machos, a redução foi de 41 e $49 \%$, para as concentrações de 10 e 50 ppm, respectivamente (Figura 6).

Resultados semelhantes foram obtidos por Asai et al. (1985), com a espécie Nilaparvata lugens (Hemiptera: Delphacidae). Fêmeas desta espécie mantidas em plantas de arroz, previamente tratadas com buprofezin a $250 \mathrm{e}$ 1000 ppm, apresentaram redução na longevidade de 30 e 40\%, respectivamente.

Trabalhando com a espécie Nilaparvata lugens, Kanaoka et al. (1996), notaram que ninfas fêmeas de último instar mantidas em plantas de arroz tratadas com $10 \mathrm{ppm}$ de buprofezin e que passaram pela última ecdise, apresentaram redução na longevidade de $74 \%$. 


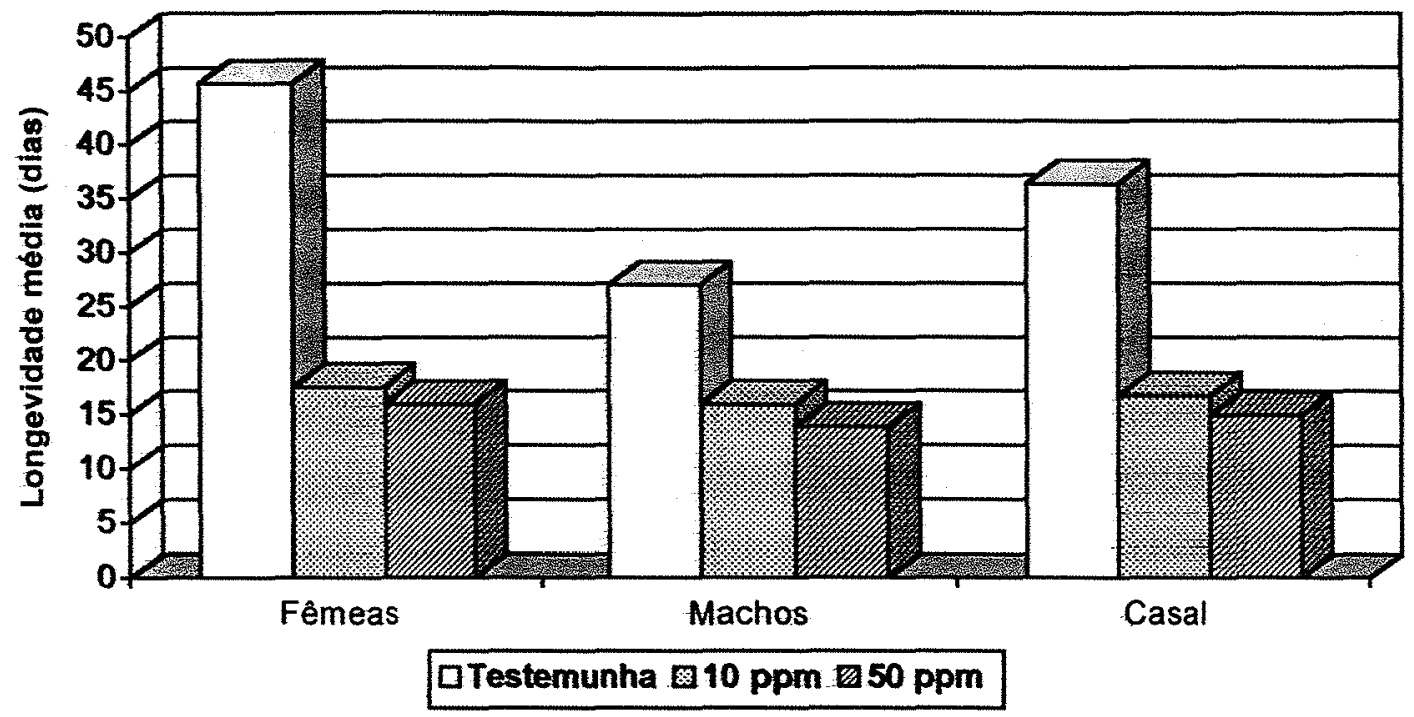

Figura 5. Longevidade média em dias para fêmeas, machos e casais adultos de E. kraemeri, em função da contaminação em diferentes concentraçöes de buprofezin, em bioensaio de contato residual.

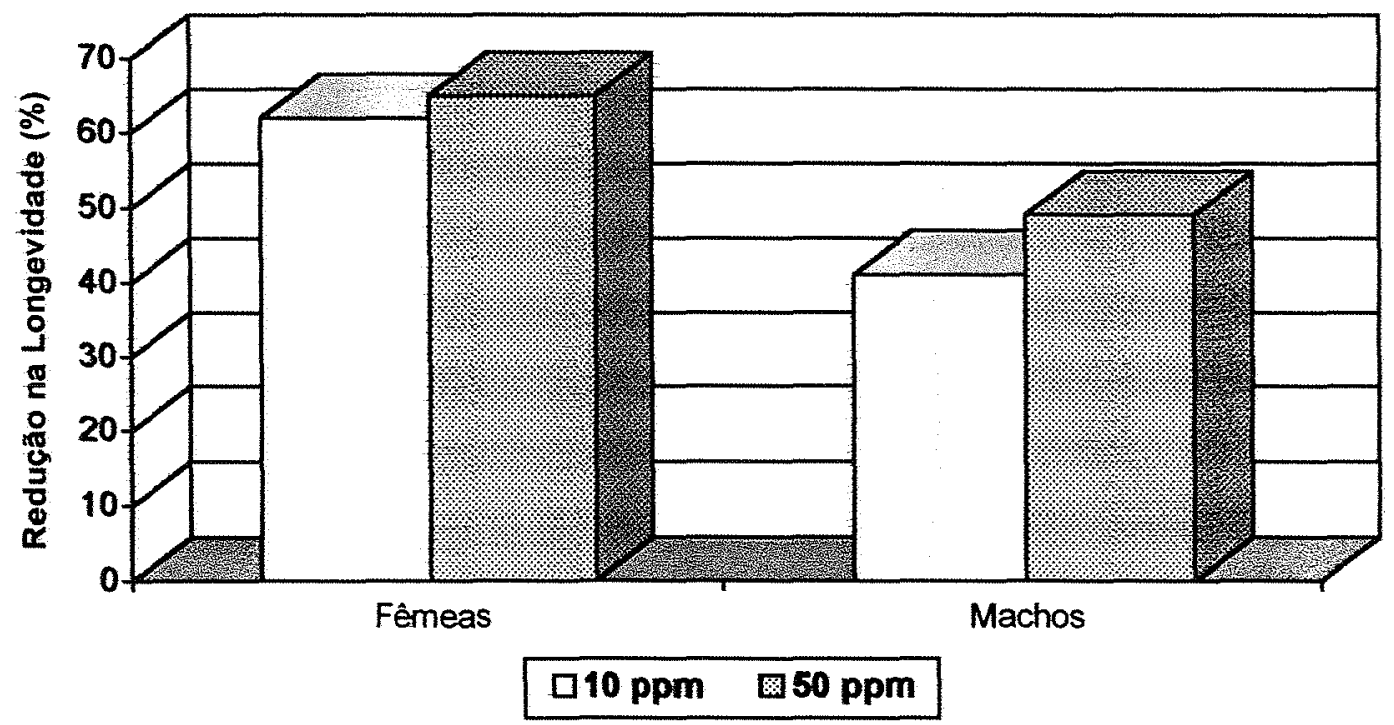

Figura 6. Redução na longevidade média para fêmeas e machos adultos de $E$. kraemeri, em função da contaminação em diferentes concentrações de buprofezin, em bioensaio de contato residual. 
$E$ interessante ressaltar que 0 inseticida buprofezin tem como principal mecanismo de ação a inibição na biossíntese de quitina. Entretanto, ainda não se sabe como se dá esta inibição. Kobayashi et al. (1989) e De Cock \& Degheele (1993) comprovaram experimentalmente que 0 inseticida buprofezin apenas mostra redução na biossíntese de quitina após a apólise, ou seja, na fase em que o nivel de 20-hidroxiecdisônio está decaindo. Os autores acreditam que o buprofezin inibe a queda no nível deste hormônio que é fundamental para a biossíntese de quitina após a apólise.

É provável que ocorra também desbalanço hormonal no nível de 20 hidroxiecdisônio nos insetos adultos, de forma a interferir na sobrevivência, visto que, este hormônio continua desempenhando importante papel nesta fase.

\subsubsection{Efeito sobre a fecundidade}

Além da redução acentuada na longevidade em função da contaminação com o inseticida buprofezin, o efeito mais acentuado deste composto foi notado quando foi feita a contagem dos ovos colocados nos diferentes tratamentos. Foi observado que as fêmeas do tratamento testemunha colocaram em média 406 ovos por parcela (4 fêmeas), ao passo que nos tratamentos em que as plantas foram previamente imersas em soluções de buprofezin a 10 e $50 \mathrm{ppm}$, o número médio de ovos colocados por 4 fêmeas foi de 3,5 e 0,5 por parcela, respectivamente (Tabela 3 e Figura 7 ).

A postura foi reduzida em 99,1 e $99,9 \%$, ou seja, quase que totalmente inibida em função da contaminação dos casais em plantas tratadas com 10 e 50 ppm, respectivamente.

Poderíamos pensar que a redução na postura teria ocorrido em função da redução acentuada na longevidade. Entretanto, observando-se o ritmo de postura das fêmeas nos diferentes tratamentos, que é um parâmetro que leva em consideração a longevidade, nota-se que, na testemunha foram colocados em média 2,38 ovos / fêmea / dia, ao passo que na concentração de 10 e 50 
ppm estes valores foram de 0,08 e 0,01 ovos / fêmea / dia, respectivamente (Tabela 3 e Figura 7).

Tabela 3. Número médio de ovos colocados por parcela (4 casais) e ritmo médio de postura por fêmea de $E$. kraemeri, em função da exposição em diferentes concentrações de buprofezin, em bioensaio de contato residual.

\begin{tabular}{ccc}
\hline TRATAMENTO & $\begin{array}{c}\text { POSTURA } \\
\text { (№ OVOS / PARCELA) }\end{array}$ & $\begin{array}{c}\text { RITMO DE POSTURA } \\
\text { (№ OVOS / FEMEA / DIA) }\end{array}$ \\
\hline TESTEMUNHA & $406,0 \mathrm{a}$ & $2,38 \mathrm{a}$ \\
$10 \mathrm{ppm}$ & $3,5 \mathrm{~b}$ & $0,08 \mathrm{~b}$ \\
$50 \mathrm{ppm}$ & $0,5 \mathrm{~b}$ & $0,01 \mathrm{~b}$ \\
\hline C.V. & 55,48 & 39,74 \\
F calc. & 37,85 & 68,02 \\
G.L & 2 & 2 \\
Pr $>$ F & 0,0001 & 0,0001
\end{tabular}

Médias seguidas pelas mesmas letras não diferem estatisticamente pelo teste de Tukey a $5 \%$ de significância.

Também foi notada redução na postura para a espécie Nilaparvata lugens da ordem de 65 e 94\%, quando os insetos foram mantidos em plantas de arroz previamente tratadas com buprofezin a 10 e 50 ppm, respectivamente. Este problema foi completamente revertido fazendo-se a aplicação de prostaglandina $\mathrm{E}_{2}$ (Uchida et al., 1987). Concluiu-se ainda neste trabalho, que a síntese de prostaglandina $E_{2}$ nas fêmeas foi inibida em 49 e $84 \%$ quando mantidas em plantas de arroz a 10 e 50 ppm, respectivamente.

Izawa et al. (1986), também notaram redução na postura em fêmeas de Henosepilachna vigintioctopunctata (Coleoptera: Coccinelidae), alimentadas com folhas de tomate tratadas com buprofezin a 1000 ppm. Este efeito também foi conseguido fazendo-se a aplicação de aspirina, um composto já reconhecido 
como inibidor da biossíntese de prostaglandina $E_{2}$ (Stanley-Samuelson \& Pedibhlota, 1996). Entretanto, a redução na postura foi novamente revertida fazendo-se a aplicação de prostaglandina $E_{2}$.

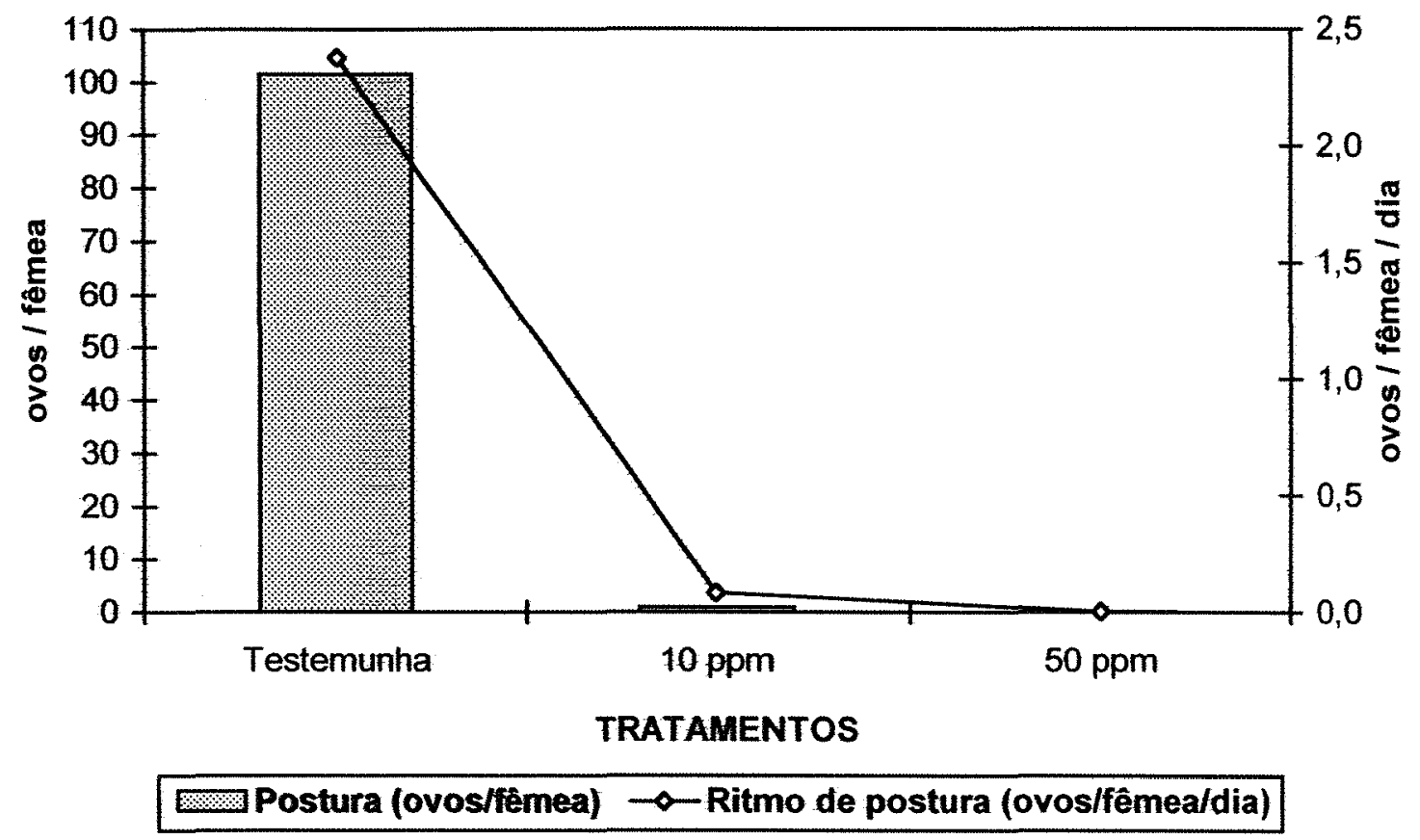

Figura 7. Postura e ritmo de postura médios para fêmeas de E. kraemeri, em função da contaminação em diferentes concentrações de buprofezin, em bioensaio de contato residual.

Não se sabe ainda como se dá o processo de inibição da síntese de prostaglandina $E_{2}$ pelo buprofezin nos insetos. $O$ fato é que isto ocorre e certamente influencia negativamente o processo de postura em Nilaparvata lugens (Hemiptera: Delphacidae) e Henosepilachna vigintioctopunctata (Coleoptera: Coccinelidae).

Pode-se supor que, a redução bastante acentuada na postura de Empoasca kraemeri verificada no presente trabalho, decorra da inibição da síntese de prostaglandina $E_{2}$, um composto já comprovadamente importante no processo de postura de algumas espécies de insetos (Destephano \& Brady, 
1977; Loher, 1979; Stanley-Samuelson et al., 1986; Ai et al., 1986; Sugawara, 1986 e Murtaugh \& Denlinger, 1987), cuja biossíntese é inibida pela presença de buprofezin (Uchida et al., 1987 e lzawa et al., 1986).

Em trabalhos futuros, seria interessante verificar se 0 inseticida buprofezin também mostra efeitos adversos sobre a postura e longevidade de adultos de várias idades de Empoasca kraemeri, visto que, neste bioensaio somente foram usados indivíduos recém emergidos com no máximo 12 horas de idade.

\subsubsection{Contaminação de machos ou fêmeas em bioensaio de contato residual}

\subsubsection{Efeito sobre a longevidade}

Foi observado que a longevidade de fêmeas e machos do tratamento testemunha foi de 45,7 e 27,0 dias, respectivamente. Quando as fêmeas foram tratadas e acasaladas com machos que não foram previamente contaminados com buprofezin, a longevidade foi de 34,8 e 22,6 dias para fêmeas e machos, respectivamente. Entretanto, o efeito mais acentuado foi notado quando somente os machos foram tratados com o inseticida. Neste caso, a longevidade para fêmeas e machos foi de 27,1 e 12,8 dias, respectivamente (Tabela 4 e Figura 8).

Assim, pode-se dizer que no tratamento em que só as fêmeas foram previamente tratadas, a redução na longevidade foi da ordem de 24 e $16 \%$ para fêmeas e machos, respectivamente. Entretanto, a maior redução na longevidade foi notada quando somente os machos foram previamente contaminados com buprofezin a $1000 \mathrm{ppm}$. Neste caso, verificou-se redução na longevidade para fêmeas e machos de 41 e $53 \%$ (Figura 9). É interessante notar que as fêmeas deste tratamento, apesar de não receberem o inseticida diretamente, mostraram longevidade bem abaixo da observada quando 
receberam-no via contato residual. Quanto aos machos, estes foram ainda mais prejudicados pelo inseticida buprofezin quanto a longevidade, quando comparado às fêmeas.

Tabela 4. Longevidade média em dias para fêmeas e machos adultos de $E$. kraemeri, em função do sexo tratado com buprofezin a 1000 ppm, em bioensaio de contato residual.

\begin{tabular}{|c|c|c|}
\hline \multirow{3}{*}{ TRATAMENTO } & \multicolumn{2}{|c|}{ LONGEVIDADE MÉDIA (DIAS) } \\
\hline & FÉMEAS & MACHOS \\
\hline & Média Original & Média Origina \\
\hline TESTEMUNHA & $45,7 a$ & $27,0 \mathrm{~b}$ \\
\hline FÊMEA TRAT. & $34,8 a b$ & $22,6 \mathrm{bc}$ \\
\hline MACHO TRAT. & $27,1 a b$ & 12,8 \\
\hline C.V. $=29,18 \%$ & $F_{\text {calc }}=8,22$ & $\operatorname{Pr}>F=$ \\
\hline
\end{tabular}

Médias seguidas pelas mesmas letras näo diferem estatisticamente pelo teste de Tukey a $5 \%$ de significância.

Não se sabe por que isto acontece, o fato é que, ou a ausência precoce dos machos levaria a redução na longevidade das fêmeas, ou o inseticida buprofezin age sobre algum fator nos machos que seriam transferidos durante a cópula para as fêmeas e que determinaria maior longevidade destas. 


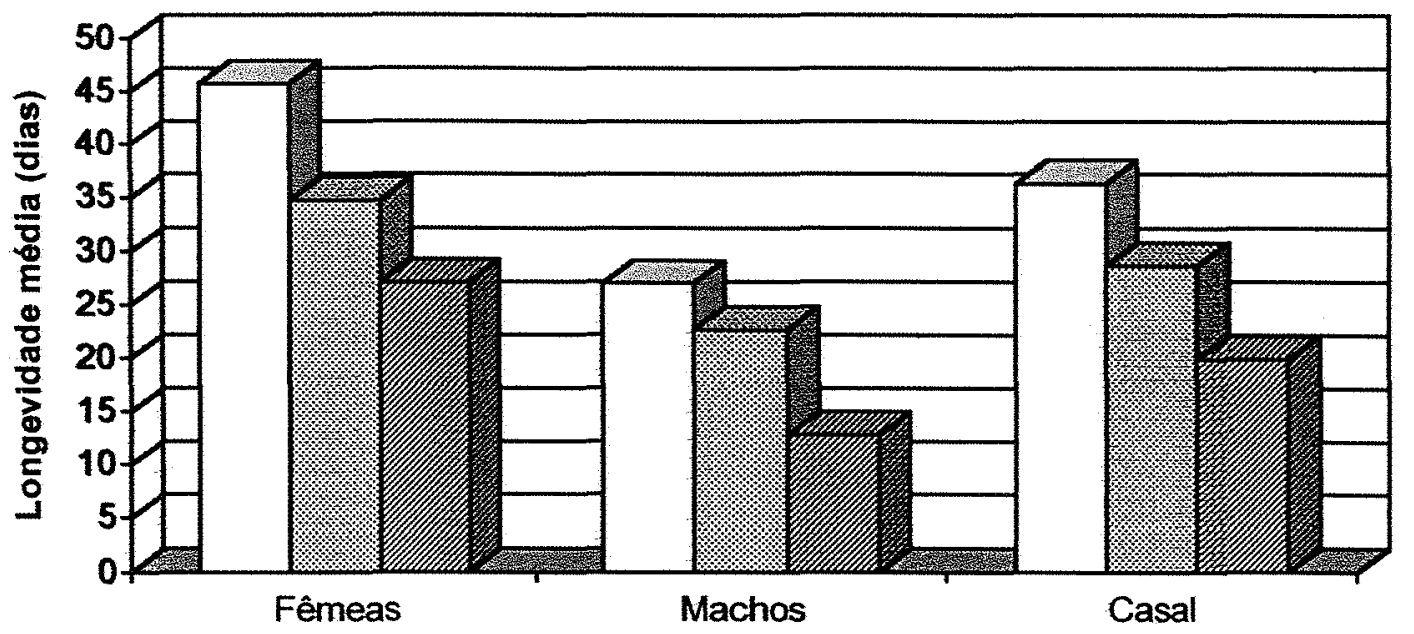

\section{Testemunha Fémeas Tratadas 0 Machos tratados}

Figura 8. Longevidade média em dias para fêmeas, machos e casais adultos de E. kraemeri, em função do sexo tratado com buprofezin a 1000 ppm, no bioensaio de contaminação em superfície tratada.

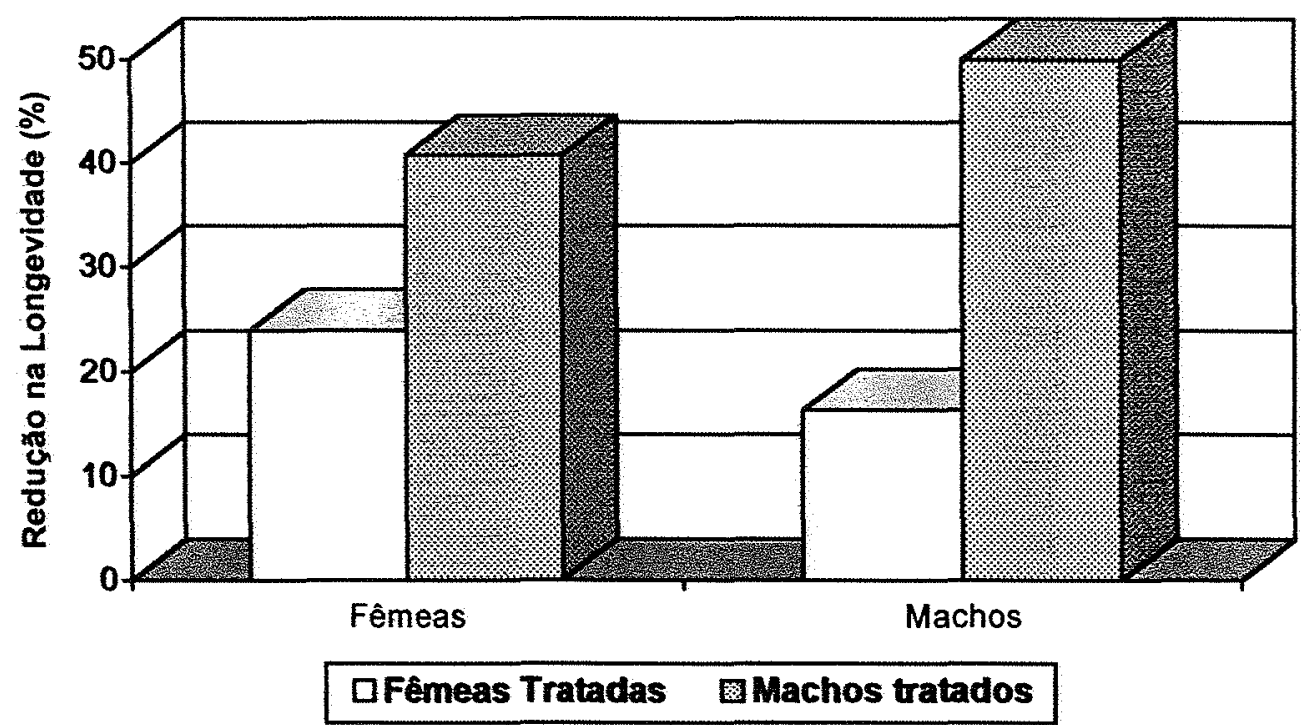

Figura 9. Redução na longevidade média para fêmeas e machos adultos de $E$. kraemeri, em função do sexo tratado com buprofezin a 1000 ppm, no bioensaio de contaminação em superfície tratada. 


\subsubsection{Efeito sobre a fecundidade}

Observando a Tabela 5 e Figura 10, pode-se notar que o tratamento em que somente fêmeas ou machos foram previamente contaminados com o inseticida buprofezin, foram encontrados em média 291,5 e 234,5 e ovos/parcela, contra 406 ovos/parcela, no tratamento testemunha.

Pode-se dizer que a redução no número de ovos colocados por parcela foi da ordem de 28 e $42 \%$, quando somente fêmeas ou machos foram previamente contaminados com buprofezin a $1000 \mathrm{ppm}$, respectivamente.

Entretanto, o ritmo de postura, que leva em consideração a longevidade, não apresentou diferenças entre os tratamentos (Tabela 5).

Tabela 5. Número médio de ovos colocados por parcela (4 casais) e ritmo médio de postura por fêmea de $E$. kraemeri, em função do sexo tratado com buprofezin a 1000 ppm, em bioensaio de contato residual.

\begin{tabular}{ccc}
\hline TRATAMENTO & $\begin{array}{c}\text { POSTURA } \\
\text { (№ OVOS / PARCELA) }\end{array}$ & $\begin{array}{c}\text { RITMO DE POSTURA } \\
\text { (No OVOS / FÊMEA / DIA) }\end{array}$ \\
\hline TESTEMUNHA & $406,0 \mathrm{a}$ & $2,38 \mathrm{a}$ \\
FÊMEAS TRATADAS & $291,5 \mathrm{a}$ & $2,45 \mathrm{a}$ \\
MACHOS TRATADOS & $234,5 \mathrm{a}$ & $2,53 \mathrm{a}$ \\
\hline C.V. & 29,89 & 26,76 \\
F calc. & 3,54 & 0,06 \\
G.L. & 2 & 2 \\
Pr $>$ F & 0,0735 & 0,9437
\end{tabular}

Médias seguidas pelas mesmas letras não diferem estatisticamente pelo teste de Tukey a $5 \%$ de significância.

O tratamento em que somente as fêmeas receberam aplicação prévia de buprofezin, a longevidade sofreu redução de $24 \%$ (Tabela 4) e a postura de 
$28 \%$ (Tabela 5). Ainda, quando somente os machos foram previamente contaminados, a longevidade das fêmeas sofreu redução de $41 \%$ e a postura em $42 \%$. Nota-se que existe uma relação bastante próxima entre o percentual de redução da longevidade de fêmeas e a redução na postura.

Deduz-se então que, a redução na postura decorreu da redução na longevidade das fêmeas para este bioensaio.

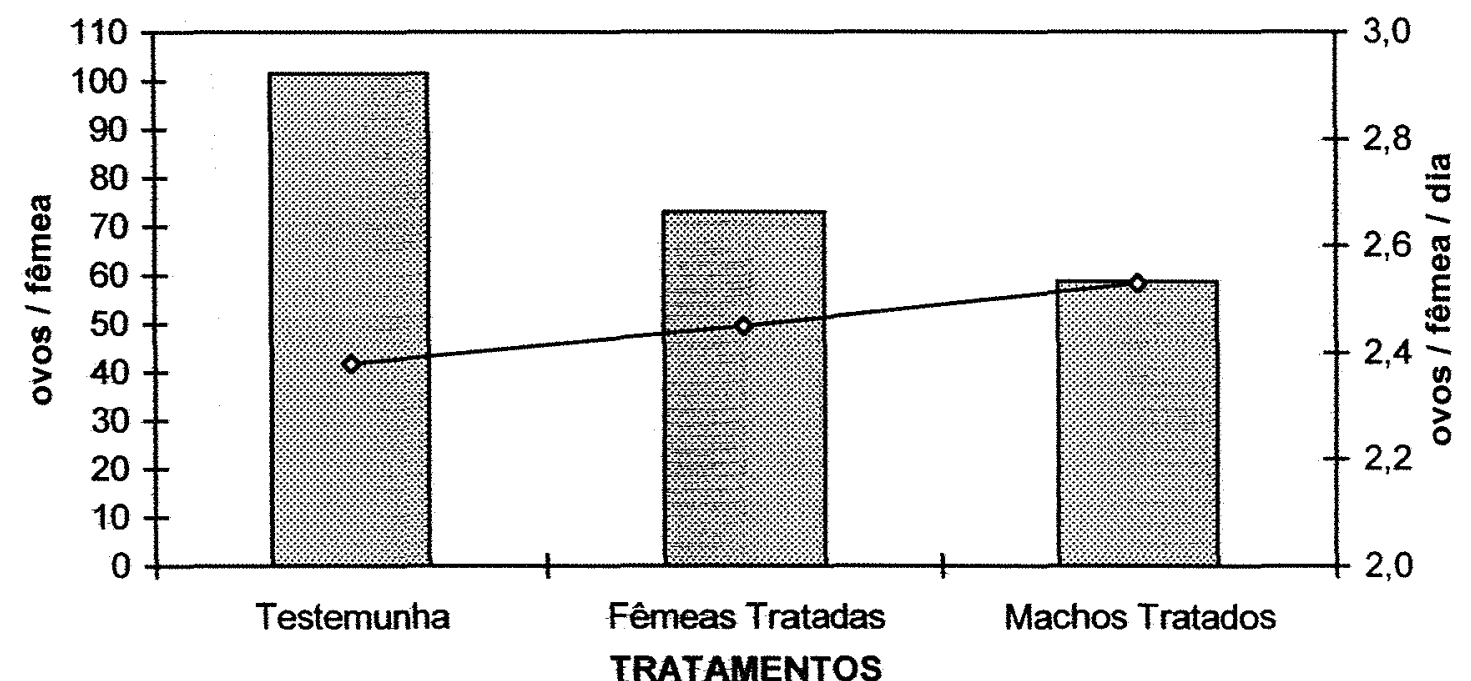

Postura (ovos/fêmea) - - Ritmo de postura (ovos/fêmea/dia)

Figura 10. Postura e ritmo de postura médios para fêmeas de $E$. kraemeri, em função do sexo tratado com buprofezin a 1000 ppm, no bioensaio de contaminação em superfície tratada.

Yasui et. al. (1987), notaram que a contaminação de adultos de Trialeurodes vaporariorum, com buprofezin via contato residual em folhas de tomate, levaram a redução na eclosão das ninfas provenientes de fêmeas contaminadas. Entretanto, para que o inseticida buprofezin mostrasse redução na eclosão das ninfas, era necessário o contato constante dos insetos com o inseticida, visto que adultos mantidos em folhas tratadas com $100 \mathrm{ppm}$ de buprofezin por 24 horas e transferidos para folhas não tratadas, mostraram 
redução significativa na eclosão somente dos ovos colocados de 0 a 24 horas após a retirada dos adultos do contato com folhas tratadas (Yasui et al., 1987).

Este efeito também foi comprovado ao verificar a ação do buprofezin sobre a fecundidade de Bemisia tabaci. Notou-se que, a eclosão de ninfas foi totalmente prejudicada quando foi avaliado ovos provenientes de adultos que foram mantidos durante todo o tempo em contato com plantas de algodão contaminadas com buprofezin a 62,5 ppm e por pelo menos 24 horas (Ishaaya et al., 1988).

É provável que o pouco tempo de exposição a que foram submetidos os insetos, neste tipo de bioensaio em que os adultos são tratados alternadamente, a redução na postura de Empoasca kraemeri não foi muito pronunciada, pois as cigarrinhas não ficaram em constante contato com 0 inseticida. Entretanto, foi possível demonstrar que os machos foram mais prejudicados que as fêmeas, levando-se em consideração a longevidade.

Aliado a alta eficácia de buprofezin sobre a fase jovem de vários representantes de Hemiptera-Auchenorryncha, a esterilização química também mostra-se interessante do ponto de vista de controle, visto que, insetos contaminados com este inseticida e portanto, inaptos para reprodução, poderiam acasalar-se sem deixarem descendentes.

Com base nos resultados obtidos neste trabalho, corroborado por outros encontrados na literatura, tornam-se promissoras pesquisas visando a esterilização química com buprofezin de outras espécies de HemipteraAuchenorryncha, dentre as quais podem ser citadas: as cigarrinhas transmissoras da clorose variegada dos citros, a espécie Dalbulus maidis que vem assumindo importância para a cultura do milho, a cigarrinha Agallia sp. uma nova praga que vem causando problemas em plantas de algodão, entre outras. 


\section{CONCLUSÕES}

Levando-se em consideração as condições em que foram conduzidos os experimentos e com base nos resultados obtidos, pode-se concluir que 0 inseticida buprofezin:

- apresentou alta toxicidade sobre ninfas de primeiro instar de Empoasca kraemeri em bioensaio de contato residual;

- levou a redução acentuada na postura e longevidade de fêmeas e machos da cigarrinha verde do feijoeiro;

- mostrou efeito adverso mais acentuado sobre os machos do que fêmeas de Empoasca kraemeri. 


\section{REFERÊNCIAS BIBLIOGRÁFICAS}

Al, N.; KOMATSU, S.; KUBO, I.; LOHER, W. Manipulation of prostaglandinmediated oviposition after mating in Teleogryllus commodus. International Journal of Invertebrate Reproduction and Development, v.10, p.33-42, 1986.

ABBOTT, W. S. A method of computing the effectiveness of an insecticide. Journal of Economic Entomology, v. 18, p.265-267, 1925.

ANUÁRIO ESTATÍSTICO DO BRASIL - IBGE, v.58, p.3-29, 1998.

ASAI, T.; FUKADA, M. Studies on the mode of action of buprofezin I.

Numphicidal and ovicidal activities on the brown rice planthopper, Nilaparvata lugens STAL (Homoptera: Delphacidae). Applied Entomology and Zoology, v.18, n.4, p.550-552, 1983.

ASAI, T.; KAJIHARA, O.; FUKADA, M.; MAEKAWA, $S$. Studies on the mode of action of buprofezin. II. Effects on reproduction of the brown planthopper, Nilaparvata lugens Stal (Homoptera: Delphacidae). Applied Entomology and Zoology, v.20, n.2, p.111-117, 1985.

BEEVI, S. P.; BALASUBRAMANIAN, M. Effect of buprofezin on adult life span, oviposition, egg hatch and progeny production of the cotton whitefly, Bemisia tabaci. Phytoparasitica, v.19, n.1, p.33-47, 1991.

BEI, Y.; GU, X.; CHEN, H., GAO, C.; BEI, Y. M.; GU, X. H.; CHEN, H. P., GAO, C. $X$. Studies on the action way of insect growth regulator, buprofezin for the brown planthopper, Nilaparvata lugens Stal. Acta Agriculturae Shejiangensis, v.8, n.1, p.30-33, 1996. /Resumo em CAB Abstracts on CD-ROM, 1996-10/1997/ 
BRENNER, R. R.; BERNASCONI, A. Prostaglandin biosynthesis in the gonads of the hematophagus insect Triatoma infestans. Comparative Biochemistry and Physiology, v.93B, n.1, p.1-4, 1989.

BORTOLI, S. A. de; GIACOMINI, P. I. Ação de alguns inseticidas granulados sistêmicos sobre Bemisia tabaci Gennadius, 1889) (Homoptera Aleyrodidae) e Empoasca kraemeri Ross \& Moore, 1957 (Homoptera Cicadellidae) e seus efeitos na produtividade do feijoeiro (Phaseolus vulgaris L.). Anais da Sociedade Entomológica do Brasil, v.10, n.1, p.97-104, 1981.

BORTOLI, S. A. de; BANZATTO, D. A.; QUINTINO FILHO, A. A.. Empoasca kraemeri Ross \& Moore, 1957 (Hom. - Cicadellidae) e Caliothrips brasiliensis (Morgan, 1929) (Thys. - Thripidae): local de ataque e influência de cobertura de solo em suas populações e na produtividade do feijoeiro (Phaseolus vulgaris L.). Ecossistema, v.11, p.34-42, out/1986.

CAETANO, W.; BERTOLDO, N.; CARLESSI, L. R.; HEINECK, M. A.; EICK, V.

$L$. Teste de inseticidas no controle da cigarrinha verde Empoasca kraemeri (Ross \& Moore, 1957) (Homoptera, Cicadellidae) na cultura do feijoeiro. Agronomia Sulriograndense, v.23, n.1, p.103-108, 1987.

CARLSON, O. V.; HIBBS. E. T. Direct counts of potato leafhopper, Empoasca fabae, eggs in Solanum leaves. Annals of the Entomological Society of America, v.55, p.512-515. 1962.

CARVAlHo, G. A.; SALGado, L. O; Rigitano, R. L.; Velloso, A. H. P. P. Efeitos de compostos reguladores de crescimento de insetos sobre adultos de Ceraeochrysa cubana (Hagen) (Neuroptera: Chrysopidae). Anais da Sociedade Entomológica do Brasil, v.23, n.2, p.335-339, $1994 a$.

CARVALHO, G. A.; TIRONI, P.; RIGITANO, R. L.; SALGADO, L. O. Seletividade de inseticidas reguladores de crescimento de insetos à 
Trichograma pretiosum Riley (Hymenoptera: Trichogrammatidae). Anais da Sociedade Entomológica do Brasil, v.23, n.7, p.431-434, $1994 b$.

CASTAÑER, M.; GARRIDO, A. Toxicidad producida por contacto y persistencia de diversos plaguicidas sobre tres insectos utilizados en control biologico: Cryptolaemus montrouzieri, Lysiphlebus testaceipes y Encarsia formosa. Investigacion Agraria: Produccion y proteccion vegetales, v.10, n.1, p.139-147, 1995.

CONSELHO NACIONAL DE ABASTECIMENTO. Indicadores da agropecuária. http://www.conab.gov.br/publicacoes/indicadores/estsafra. cfm (10 Jul. 2000).

COSTA, J. M. da; SAMPAIO, L. S. V.; BUHR, K. L.; COSTA, J. A. Controle da cigarrinha verde, Empoasca kraemeri Ross \& Moore, 1957 (Homoptera, Cicadellidae) em feijão macassar, (Vigna unguiculata L. WALP) com inseticidas sistêmicos. Anais da Sociedade Entomológica do Brasil, v.15, n.1, p.39-45, 1986.

DAÍ, Z. Y.; YANG, Y. Z.; HUANG, D. L.; LIU, S. Z. A study on the systemic action of buprofezin. Plant Protection, v.18, n.4, p.32, 1992. /Resumo em CAB Abstracts on CD-ROM, 1995/

De COCK, A.; DEGHEELE, D. Cytochemical demonstration of chitin incorporation in the cuticle of Trialeurodes vaporariorum (Westwood) (Homoptera: Aleyrodidae) after buprofezin treatment. International Journal of Insect Morphology \& Embriology, v.22, n.2-4, p.119-125, 1993.

DEMÉTRIO, C. G. B. A superdispersão em dados de proporção de brotação da cana-de-açúcar e de proporção de perfilhos com carvão. Piracicaba, 1994. 165p. Tese (Livre-Docência) - Escola Superior de Agricultura "Luiz de Queiroz", Universidade de São Paulo. 
DESTEPHANO, B. D.; BRADY, U. E. Prostaglandin and prostaglandin synthetase in the cricket, Acheta domesticus. Journal of Insect Physiology, v.23, p.905-911, 1977.

FANCELLI, A. L. A cultura do feijão irrigado. Piracicaba: ESALQ, Departamento de Agricultura, 1990. 136p.

GALLO, D.; NAKANO, O.; SILVEIRA NETO, S.; CARVALHO, R. P. L; BATISTA, G. C.; BERTI FILHO, E.; PARRA, J. R. P.; ALVES, S. B.; VENDRAMIM, J. D. Manual de entomologia agrícola. $2^{a}$ ed. Piracicaba: Editora Agronômica "Ceres", 1988. 649p.

GARRIDO, A.; BEITIA, F.; GRUENHOLZ, P. Effects of PP618 on imature stages of Encarsia formosa and Cales noacki (Hymenoptera: Aphelinidae). Proceedings of Brithish Crops Protection Conference - Pests and Diseases, v.1, p.305-310, 1984.

GERLING, D.; SINAI, P. Buprofezin effects on two parasitoid species of whitefly (Homoptera: Aleyrodidae). Journal of Economic Entomology, v.87, n.4, p.842-846, 1994.

GONZÁLEZ, A.; CAVE, R. D. Comparación del parasitismo de huvevos de Empoasca kraemeri Ross y Moore (Homoptera: Cicadellidae) por Anagrus spp. (Hymenoptera: Mymaridae) en frijol común en labranza cero y labranza convencional. Ceiba, v.38, n.1, p.49-54, 1997.

GRAVENA, S.; FERNANDES, O. D.; SANTOS, A. C.; PINTO, A. S.; PAIVA, P. S. B. Efeito de buprofezin e abamectin sobre Pentilia egena (MULS.) (Coleoptera: Coccinellidae) e crisopídeos em citros. Anais da Sociedade Entomológica do Brasil, v.21, n.1, p.215-222, 1992.

HAGEN, D. V; BRADY, U. E. Prostaglandins in the cabbage looper, Trichoplusia ni. Journal of Insect Physiology, v.28, p.761-765, 1982. 
HAYASHI, $H$. Side effects of pesticides on Encarsia formosa Gahan. Bulletin of the Hiroshima Prefectural Agriculture Research Center, v.64, p.33-43, 1996. /Resumo em CAB Abstracts on CD-ROM, 1996-10/1997/

HEYER, W.; CHIANG, L. M. L.; CRUZ, B. On the fertility, mortality and age structure of Empoasca kraemeri (Ross \& Moore) populations on beans (Phaseolus vulgaris L.) in Cuba. Archiv fur Phytopathologie und Pfanzenschutz, v.27, n.3, p.229-238, 1991. /Resumo em CAB Abstracts on CD-ROM, 1990-1991/

HEYER, W.; DAMMER, K. D. The horizontal and vertical distribution of Empoasca kraemeri (Ross and Moore) in bean fields (Phaseolus vulgaris L.), the population dynamics and recommendations for the monitoring in the field under tropical conditions. Zeitschrift fur Pflanzenkrankheiten und Pflanzenschutz, v.103, n.4, p.383-396, 1996. /Resumo em CAB Abstracts on CD-ROM, 1998/08-1999/01/

HEYER, W.; STERNKOPF, G.; CHIANG, L. M. L.; CRUZ, B. On the damaging effect of the cicada Empoasca kraemeri (Ross and Moore) in beans (Phaseolus vulgaris L.). Beitrage zu Entomologie, v.39, n.2, p.383-389, 1989. /Resumo em CAB Abstracts on CD-ROM, 1990-1991/

HINDE, J.; DEMÉTRIO, C. G. B. Overdispersion: models and estimation. São Paulo: ABE, 1998. 73p.

HU, L. C.; ZHANG, Z. H.; HU, L. C.; ZHANG, Z. Y. Control of Empoasca flavescens with $20 \%$ buprofezin EC. Plant Protection, v.19, n.6, p.47, 1993. /Resumo em CAB Abstracts on CD-ROM, 1995/

ISHAAYA, I.; MENDELSON, Z.; MELAMED-MADJAR, V. Effect of buprofezin on embryogenesis and progeny formation of sweetpotato withefly (Homoptera: Aleyrodidae). Journal of Economic Entomology, v.81, n.3, p.781-784, 1988. 
IZAWA, Y.; UCHIDA, M.; SUGIMOTO, T.; ASAI, T. Inhibition of chitin biosynthesis by buprofezin analogs in relation to their activity controlling Nilaparvata lugens Stal. Pesticide Biochemistry and Physiology, v.24, p.343-347, 1985.

IZAWA, Y.; UCHIDA, M.; YASUI, M. Mode of action of buprofezin on the twenty-eight spotted ladybird, Henosepilachna vigintioctopunctata Fabricus. Agricultural and Biological Chemistry Journal, v.50, n.5, p.1369-1371, 1986.

JARVIS, T. D.; EARLEY, F. G. P.; REES, H. H. Inhibition of the ecdysteroid biosynthetic pathway in ovarian follicle cells of Locusta migratoria. Pesticide Biochemistry and Physiology, v.48, p.153-162, 1994.

JONES, W. A.; CIOMPERLIK, M. A.; WOLFENBARGER, D. A. Lethal and sublethal effects of insecticides on two parasitoides attacking Bemisia argentifolii (Homoptera: Aleyrodidae). Biological Control, v.11, p.70-76, 1998.

KANAOKA, A.; YAMAGUCHI, R.; KONNO, T. Effect of buprofezin on oviposition of brown planthopper, Nilaparvata lugens, at sub-lethal dose. Journal of Pesticide Science, v.21, p.152-157, 1996.

KOBAYASHI, M.; UCHIDA, M.; KURIYAMA, K. Evaluation of 20hydroxyecdysone level by buprofezin in Nilaparvata lugens Stal nymphs. Pesticide Biochemistry and Physiology, v.34, n.1, p.9-16, 1989.

LACERDA, C. A. de; MORAES, G. J. de; HAJI, F. N, P. Controle químico da cigarrinha-verde-do-feijoeiro. Anais da Sociedade Entomológica do Brasil, v.17, n.supl., p.133-139, 1988.

LAI, C. B. Test on the control of Empoasca flavescens and E. pirisuga by Applaud. Entomological Knowledge, v.30, n.5, p.286-287, 1993. /Resumo em CAB Abstracts on CD-ROM, 1995/ 
LANGE, A. B. The transfer of prostaglandin-synthesizing activity during mating in Locusta migratoria. Insect Biochemistry, v.14, n.5, p.551-556, 1984.

LEITE, L. G.; ALVES, S. B.; GALAINI-WRAIGHT, S. P.; ROBERTS, D. W. Comportamento de isolados do fungo Zoophthora radicans sobre Empoasca kraemeri. Ecossistema, v.21, p.16-22, Dez/1996.

LEITE FILHO, A. S.; RAMALHO, F. S. Biologia da cigarrinha verde Empoasca kraemeri Ross \& Moore, 1957 em feijão e em feijão de corda. Anais da Sociedade Entomológica do Brasil, v.8, n.1, p.93-101, 1979.

LOHER, W. The influence of prostaglandin $E_{2}$ on oviposition in Teleogryllus comodus. Entomology Experimental \& Applied, v. 25, p.107-109, 1979.

MAGALhÃES, B. P.; YOKOYAMA, M.; ZIMMERMANN, F. J. P. Métodos de amostragem e flutuação populacional de Empoasca kraemeri ROSS \& MOORE, 1957 (Homoptera: Cicadellidae), Cerotoma arcuata (Olivier, 1791) e Diabrotica speciosa (Germar, 1824) (Coleoptera: Chrysomelidae). Anais da Sociedade Entomológica do Brasil, v.17, n.1, p.81-95, 1988.

MAYRINK, J. C.; CARVALHO, G. A.; JUNQUEIRA NETTO, A. Controle da cigarrinha-verde Empoasca kraemeri (Ross \& Moore, 1957) (Hemiptera Homoptera: Cicadellidae) no feijoeiro (Phaseolus vulgaris). Pesticidas Revista Técnico Científica, v.4, n.4, p.21-26, 1994.

MENDEL, Z.; BLUMBERG, D.; ISHAAYA, I. Effects of some insect growth regulators on natural enemies of scale insects (Hom.: Coccoidea). Entomophaga, v.39, n.2, p.199-209, 1994.

MENDEZ, H.; ORTIZ, J. C.; HALLMAN, G. Efecto del ataque de Empoasca kraemeri ROSS \& MOORE (Homoptera: Cicadellidae), sobre el rendimiento en dos variedades de frijol (Phaseolus vulgaris) en cuatro etapas de desarrollo. Acta Agronomica, v.34, n.3, p.48-57, 1984.

MEYERDIRK, D. E.; MORATORIO, M. S. Seasonal population density of Anagrus girauti (Hymenoptera: Mymaridae), an egg parasitoid of Circulifer 
tenellus and Empoasca spp. (Homoptera: Cicadellidae). Journal of Economic Entomology, v.80, n.2, p.362-365, 1987.

MORAES, G. J. de; OlIVEIRA, C. A. V.; AlBUQUERQUE, M. M. de; SALVIANO, L. M. C.; POSSÍDIO, P. L. de. Efeito da época de infestação de Empoasca kraemeri Ross \& Moore, 1957 (cigarrinha verde do feijoeiro) (Homoptera: Typhlocibidae) na cultura de Vigna unguiculata Walp (feijão macassar). Anais da Sociedade Entomológica do Brasil, v.9, n.1, p.67-74, 1980.

MURTAUGH, M. P.; DENLINGER, D. L. Regulation of long-term oviposition in the house cricket, Acheta domesticus: roles of prostaglandin and factors associated with sperm. Archives of Insect Biochemistry and Physiology, v.6, p.59-72, 1987.

OLIVEIRA, J. V.; BARROS, R.; SILVA, R. L. X.; PEREIRA, J. L. L.; VASCONCELOS, H. Influência do consórcio milho e caupi na infestação de Empoasca kraemeri Ross \& Moore e nos danos causados por Spodoptera frugiperda (J. E. Smith). Anais da Sociedade Entomológica do Brasil, v.24, n.1, p.69-76, 1995.

OLIVEIRA, J. V.; SILVA, J. V. da; FERNANDES, M. B. D. Dinâmica populacional da "cigarrinha verde" Empoasca kraemeri ROSS \& MOORE, 1957, em cultivares de feijão. Anais da Sociedade Entomológica do Brasil, v.10, n.1, p.21-26, 1981.

OSPINA, H. F. O. (Coord.) EI lorito verde (Empoasca kraemeri Ross y Moore) y su control. Colômbia: CIAT, 1980. 41p.

PAN, W. L.; CHIU, S. F. Mode of action of buprofezin against Nilaparvata lugens nymphs and its application in rice fields for the control of planthoppers. Journal of the South China Agricultural University, v.10, n.4, p.13-18, 1989. /Resumo em CAB Abstracts on CD-ROM, 1990-1991/ 
PEDROSA, F. N. T. Estudo de Empoasca kraemeri Ross e Moore, 1957 (Homoptera, Cicadellidae) em cultura de feijão. Piracicaba, 1977. 90p. Dissertação (Mestrado) - Escola Superior de Agricultura "Luiz de Queiroz", Universidade de São Paulo.

PEREIRA, J. L. L.; OLIVEIRA, J. V. de; BARROS, R.; GONDIN JR, M. G. C.; SOUZA, A. C. F. de; BARBOSA, F. T. Controle químico da cigarrinha verde Empoasca kraemeri Ross \& Moore (Homoptera: Cicadellidae) em caupi. Anais da Sociedade Entomológica do Brasil, v.22, n.3, p.497-503, 1993.

PEREIRA, R. P. Flutuação populacional da cigarrinha verde do feijão em duas épocas de semeadura. Empresa de Pesquisa Agropecuária do Estado do Rio de Janeiro. Comunicado Técnico n.184, dez/1987.

PIZZAMIGLIO, M. A. Aspectos da biologia de Empoasca kraemeri (Ross \& Moore, 1957) (Homoptera: Cicadellidae) em Phaseolus vulgaris (Linnaeus, 1753) e ocorrência de parasitismo em ovos. Anais da Sociedade Entomológica do Brasil (Comunicação científica), v.8, n.2., p.369-372, 1979.

RAMALHO, F. S. Efeitos da época de infestação da cigarrinha verde Empoasca kraemeri Ross \& Moore, 1957 (Homoptera, Typhlocibidae) na cultura do feijão. Anais da Sociedade Entomológica do Brasil, v.7, n.1., p.30-32, 1978.

RAMALHO, F. S.; RAMOS, J. R. Distribuição dos ovos de Empoasca kraemeri Ross \& Moore, 1957 na planta do feijão. Anais da Sociedade Entomológica do Brasil, v.8, n.1, p.85-91, 1979.

SEGNINI, S.; MONTAGNE, A. Biologia y ecologia poblacional de Empoasca kraemeri Ross y Moore (Homoptera, Cicadellidae) en caraota (Phaseolus vulgaris). II. Ciclo de vida, logevidad, fecundidad y sobrevivencia de $E$. kraemeri bajo condiciones de laboratorio. Agronomia Tropical, v.36, n.4-6, p.15-27, 1986a. 
SEGNINI, S.; MONTAGNE, A. Biologia y ecologia poblacional de Empoasca kraemeri Ross y Moore (Homoptera, Cicadellidae) en caraota (Phaseolus vulgaris). III. Fluctuacion poblacional de $E$. kraemeri em campos cultivados com caraota. Agronomia Tropical, v.36, n.4-6, p.29-45, 1986 b.

SEGNINI, S.; MONTAGNE, A. Biologia y ecologia poblacional de Empoasca kraemeri Ross y Moore (Homoptera, Cicadellidae) en caraota (Phaseolus vulgaris). IV. Disposicion espacial de E. kraemeri dentro de campos cultivados com caraota. Agronomia Tropical, v.36, n.4-6, p.47-62, 1986c.

SEGNINI, S.; MONTAGNE, A. Biologia y ecologia poblacional de Empoasca kraemeri Ross y Moore (Homoptera, Cicadellidae) en caraota (Phaseolus vulgaris). V. Inmigracion y emigracion de los adultos de $E$. kraemeri em um campo de caraotas. Agronomia Tropical, v.36, n.4-6, p.65-76, 1986d.

SHIBUYA, M. Applaud, a new selective inseticide. Japan Pesticide Information, n.44, p.17-21, 1984.

STANLEY-SAMUELSON, D. W. Assessing the significance of prostaglandins and other eicosanoids in insect physiology. Journal of Insect Physiology, v.40, n.1. p.3-11, 1994a.

STANLEY-SAMUELSON, D. W. Prostaglandins and related eicosanoids in insects. In: EVANS, P. D. (Ed.) Advances in insect physiology. Cambridge: Academic Press, 1994b. v.24, p.115-212.

STANLEY-SAMUELSON, D. W.; LOHER, W. Prostaglandins in insect reproduction. Annals of the Entomological Society of America, v.79, n.6, p.841-853, 1986.

STANLEY-SAMUELSON, D. W.; PEDIBHOTLA, V. K. What can we learn from prostaglandins and related eicosanoids in insects? Insect Biochemistry and Molecular Biology, v.26, n.3, p.223-234, 1996. 
STANLEY-SAMUELSON, D. W.; PELOQUIN, J. J.; WERNER; L. Egg-laying in response to prostaglandin injections in the Australian field cricket, Teleogryllus commodus. Physiological Entomology, v.11, p.213-219, 1986.

STANLEY-SAMUELSON, D. W; JURENKA, R. A.; BLOMQUIST, G. J.; LOHER, W. Sexual transfer of prostaglandin precursor in the field cricket, Teleogryllus commodus. Physiological Entomology, v.12, p.347-354, 1987.

STANLEY-SAMUELSON, D. W.; KLOCKE, J. A.; KUBO, I.; LOHER, W. Prostaglandins and arachidonic acid in nervous and reproductive tissue from virgin and mated female crickets Teleogryllus commodus. Entomology Experimental \& Applied, v.34, p.35-39, 1983.

SUGAWARA, T. Oviposition behaviour of the cricket Teleogryllus commodus: the site of action of an oviposition-stimulating factor and the role of the nervous system. Journal of Insect Physiology, v.32, n.5, p.485-492, 1986.

TURATI, J. A.; MONFERDINI, M. A.; CALAFIORI, M. H.; BATISTA, G. C. de; FRANCO, J. F.; AMARAL, L. F. do. Ensaio em feijão (Phaseolus vulgaris L.) com alguns inseticidas granulados para o controle de pragas e análise de resíduo de aldicarbe. Ecossistema, v.7, p.51-56, 1982.

UCHIDA, M.; IZAWA, Y. SUGITOMO, T. Antagonistic effect of 20hydroxyecdysone to an insect growth regulator, buprofezin, in Nilaparvata lugens Stal. Agricultural and Biological Chemistry, v.50, n.7, p.19131915, 1986.

UCHIDA, M.; IZAWA, Y. SUGITOMO, T. Inhibition of prostaglandin biosyntesis and oviposition by an insect growth regulator, buprofezin, in Nilaparvata lugens Stal. Pesticide Biochemistry and Physiology, v. 27, p. 71-75, 1987.

UCHIDA, M.; TOSHIRO, A.; SUGIMOTO, T. Inhibition of cuticle deposition and chitin biosyntesis by a new insect growth regulator, buprofezin, in Nilaparvata lugens Stal. Agricultural and Biological Chemistry Journal, v.49, n.4, p.1233-1234, 1985. 
Velloso, A. H. P. P.; Rigitano, R. L. O.; CARVAlho, G. A. de. Efeitos de compostos reguladores de crescimento de insetos sobre ovos e larvas de Chrysoperla externa (Hagen, 1861) (Neuroptera: Chrysopidae). Ciência e Agrotecnologia, v.21, n.3, p.306-312, 1997.

VIEIRA, A. M. C. Modelos para dados de proporçōes com superdispersão aplicados ao controle biológico. Piracicaba, 1998. 61p. Dissertação (Mestrado) - Escola Superior de Agricultura "Luiz de Queiroz", Universidade de São Paulo.

VIEIRA, C. Doenças e pragas do feijoeiro. Universidade Federal de Viçosa: Impr. Univ., 1983. 231p.

VIVARELLI, J. B.; OLIVEIRA JR., L. C. C. de; DEPAOLI, L. G.; SILVA, E. A. B. da; CALAFIORI, M. H.; FRANCO, J. F. Experimento para o controle de pragas do feijão, Phaseolus vulgaris L., com inseticidas para tratamento de sementes e granulado de solo. Ecossistema, v.10, p.127-138, 1985.

WAKAYAMA, E. J.; DILLWITH, J. W.; BLOMQUIST, G. J. Characterization of prostaglandin synthesis in the housefly, Musca domestica (L.). Insect Biochemistry, v.16, n.6, p. 903-909, 1986.

WILDE, G.; SCHOONHOVEN, A. van; LA-VERDE, L. G. The biology of Empoasca kraemeri on Phaseolus vulgaris. Annals of the Entomological Society of America, v.69, n.3. p.442-444. May, 1976.

YAMAJA-SETTYA, B. N. \& RMAIAH, T. R. Effect of prostaglandins \& inhibitors of prostaglandin biosynthesis on oviposition in the silkmoth Bombyx mori. Indian Journal of Experimental Biology, v.18, p.539-541, 1980.

YAMAUCHI, M.; FUGO, H.; DEDOS, S. G. Prostaglandins do not release egglaying behaviour in the silkmoth, Bombyx mori. Zoological Science, v.14, p.135-140, 1997.

YAROM, I.; BLUMBERG, D.; ISHAAYA, I. Effects of buprofezin on california red scale (Homoptera: Diaspididae) and Mediterranean black scale (Homoptera: 
Coccidae). Journal of Economic Entomology, v.81, n.6. p.1581-1585. Dec, 1988.

YASUI, M.; FUKADA, M.; MAEKAWA, S. Effects of buprofezin on reproduction of the greenhouse whitefly, Trialeurodes vaporariorum (Westwood) (Homoptera: Aleyrodidae). Applied Entomology and Zoology, v.22, n.3, p.266-271, 1987.

ZOCCHI, S. S. Misturas de modelos "logit", "probit" e "complemento log-log". Piracicaba, 1993. 129p. Dissertação (Mestrado) - Escola Superior de Agricultura "Luiz de Queiroz", Universidade de São Paulo. 


\section{APÊNDICE 1}

Tabela 6. Dados originais de longevidade de Empoasca kraemeri.

\begin{tabular}{|c|c|c|c|c|c|c|c|c|c|c|}
\hline \multirow{3}{*}{ Inseto } & \multirow{2}{*}{\multicolumn{2}{|c|}{ Testemunha }} & \multicolumn{4}{|c|}{ Bioensaio $1^{*}$} & \multicolumn{4}{|c|}{ Bioensaio $2^{\star \star}$} \\
\hline & & & \multicolumn{2}{|c|}{$10 \mathrm{ppm}$} & \multicolumn{2}{|c|}{$50 \mathrm{ppm}$} & \multicolumn{2}{|c|}{ fêmea tratada } & \multicolumn{2}{|c|}{ macho tratado } \\
\hline & fêmea & macho & fêmea & macho & fêmea & macho & fêmea & macho & fềmea & macho \\
\hline 1 & 10 & 10 & 3 & 5 & 4 & 5 & 9 & 20 & 9 & 2 \\
\hline 2 & 10 & 10 & 4 & 6 & 5 & 5 & 15 & 9 & 31 & 7 \\
\hline 3 & 11 & 11 & 4 & 8 & 6 & 5 & 17 & 17 & 24 & 4 \\
\hline 4 & 29 & 14 & 6 & 6 & 6 & 6 & 18 & 17 & 8 & 9 \\
\hline 5 & 35 & 15 & 7 & 5 & 9 & 6 & 19 & 17 & 25 & 17 \\
\hline 6 & 39 & 18 & 7 & 11 & 13 & 6 & 19 & 17 & 9 & 9 \\
\hline 7 & 43 & 20 & 8 & 9 & 15 & 6 & 27 & 17 & 32 & 20 \\
\hline 8 & 44 & 26 & 12 & 32 & 16 & 6 & 34 & 20 & 24 & 2 \\
\hline 9 & 53 & 26 & 16 & 13 & 17 & 10 & 37 & 18 & 15 & 9 \\
\hline 10 & 56 & 26 & 19 & 6 & 17 & 15 & 38 & 10 & 31 & 7 \\
\hline 11 & 60 & 27 & 25 & 15 & 18 & 16 & 41 & 15 & 34 & 7 \\
\hline 12 & 60 & 27 & 31 & 34 & 18 & 20 & 46 & 40 & 44 & 15 \\
\hline 13 & 61 & 32 & 31 & 12 & 18 & 22 & 47 & 25 & 39 & 22 \\
\hline 14 & 64 & 33 & 34 & 21 & 29 & 38 & 54 & 45 & 31 & 23 \\
\hline 15 & 67 & 67 & 36 & 25 & 29 & 42 & 62 & 46 & 31 & 27 \\
\hline 16 & 89 & 70 & 37 & 46 & 35 & - & 73 & 29 & 47 & 24 \\
\hline Média & 45,7 & 27,0 & 17,5 & 15,9 & 15,9 & 13,9 & 34,8 & 22,6 & 27,1 & 12,8 \\
\hline Casal & \multicolumn{2}{|c|}{36,3} & \multicolumn{2}{|c|}{16,7} & \multicolumn{2}{|c|}{14,9} & \multicolumn{2}{|c|}{26,7} & \multicolumn{2}{|c|}{19,9} \\
\hline
\end{tabular}

* Contaminação de casais em diferentes concentraçóes de buprofezin em bioensaio de contato residual;

** Contaminação de machos ou fêmeas com buprofezin em bioensaio de contato residual. 


\section{APÊNDICE 2}

Tabela 7. Dados originais de postura e ritmo de postura de Empoasca kraemeri.

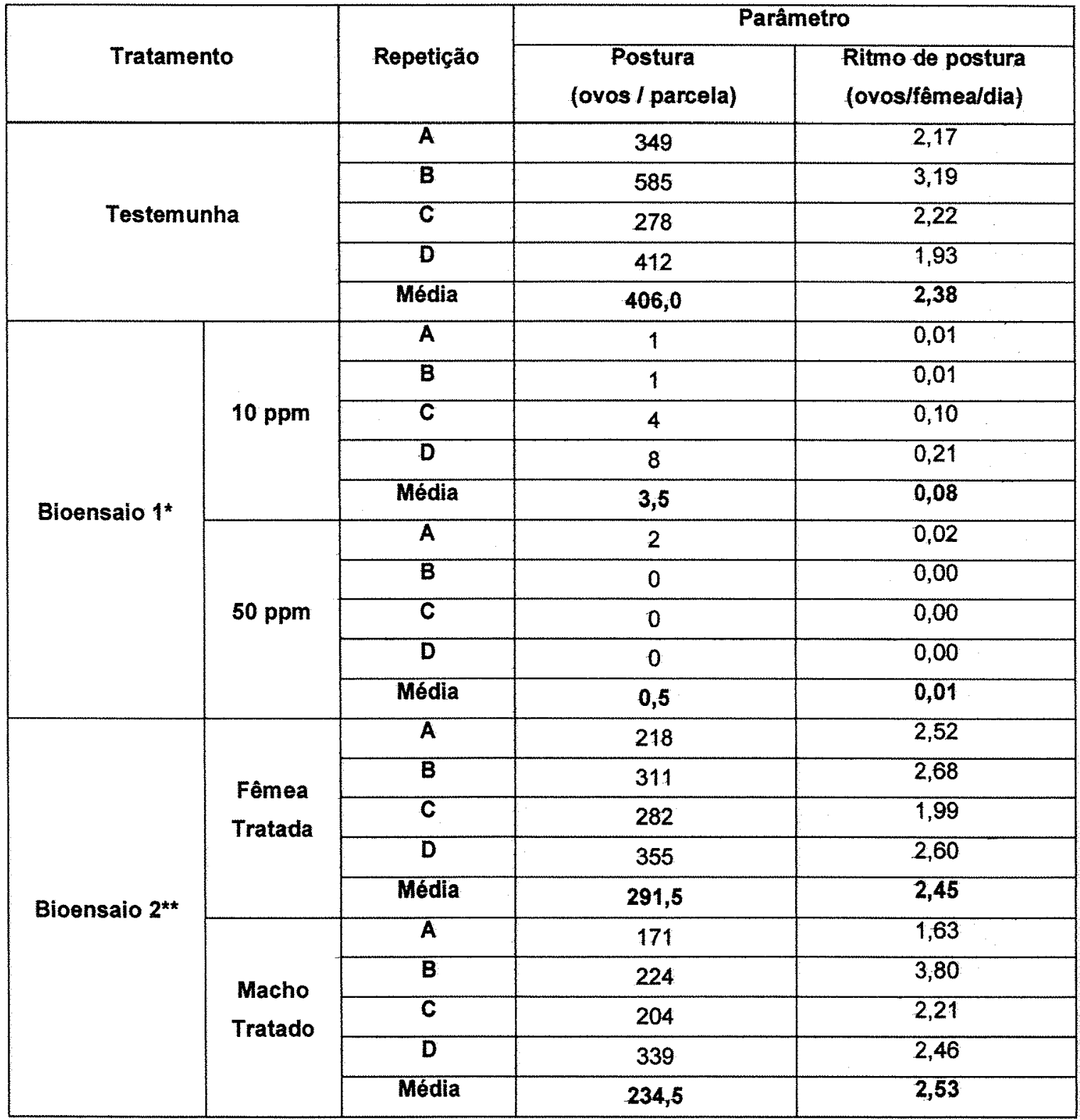

* Contaminação de casais em diferentes concentraçōes de buprofezin em bioensaio de contato residual;

** Contaminação de machos ou fêmeas com buprofezin em bioensaio de contato residual. 